\title{
Re-evaluating lipotoxic triggers in skeletal muscle: Relating intramyocellular lipid metabolism to insulin sensitivity.
}

Citation for published version (APA):

Bosma, M., Kersten, S., Hesselink, M. K. C., \& Schrauwen, P. (2012). Re-evaluating lipotoxic triggers in skeletal muscle: Relating intramyocellular lipid metabolism to insulin sensitivity. Progress in Lipid Research, 51(1), 36-49. https://doi.org/10.1016/j.plipres.2011.11.003

Document status and date:

Published: 01/01/2012

DOI:

10.1016/j.plipres.2011.11.003

Document Version:

Publisher's PDF, also known as Version of record

Document license:

Taverne

Please check the document version of this publication:

- A submitted manuscript is the version of the article upon submission and before peer-review. There can be important differences between the submitted version and the official published version of record.

People interested in the research are advised to contact the author for the final version of the publication, or visit the DOI to the publisher's website.

- The final author version and the galley proof are versions of the publication after peer review.

- The final published version features the final layout of the paper including the volume, issue and page numbers.

Link to publication

\footnotetext{
General rights rights.

- You may freely distribute the URL identifying the publication in the public portal. please follow below link for the End User Agreement:

www.umlib.nl/taverne-license

Take down policy

If you believe that this document breaches copyright please contact us at:

repository@maastrichtuniversity.nl

providing details and we will investigate your claim.
}

Copyright and moral rights for the publications made accessible in the public portal are retained by the authors and/or other copyright owners and it is a condition of accessing publications that users recognise and abide by the legal requirements associated with these

- Users may download and print one copy of any publication from the public portal for the purpose of private study or research.

- You may not further distribute the material or use it for any profit-making activity or commercial gain

If the publication is distributed under the terms of Article 25fa of the Dutch Copyright Act, indicated by the "Taverne" license above, 
Review

\title{
Re-evaluating lipotoxic triggers in skeletal muscle: Relating intramyocellular lipid metabolism to insulin sensitivity
}

\author{
Madeleen Bosma ${ }^{\text {a }}$, Sander Kersten ${ }^{\text {b }}$, Matthijs K.C. Hesselink ${ }^{c}$, Patrick Schrauwen ${ }^{\text {a,* }}$ \\ ${ }^{a}$ Department of Human Biology, NUTRIM School for Nutrition, Toxicology and Metabolism, Maastricht University Medical Centre+, 6200MD Maastricht, The Netherlands \\ ${ }^{\mathrm{b}}$ Nutrition, Metabolism and Genomics Group, Division of Human Nutrition, Wageningen University, 6700EV Wageningen, The Netherlands \\ ${ }^{\mathrm{c}}$ Human Movement Sciences, NUTRIM School for Nutrition, Toxicology and Metabolism, Maastricht University Medical Center+, 6200MD Maastricht, The Netherlands
}

\section{A R T I C L E I N F O}

\section{Article history:}

Available online 19 November 2011

\section{Keywords:}

Type 2 diabetes

Lipotoxicity

Athlete's paradox

Diacylglycerol

Ceramide

Lipid droplets

\begin{abstract}
A B S T R A C T
Ectopic fat accumulation has been linked to lipotoxic events, including the development of insulin resistance in skeletal muscle. Indeed, intramyocellular lipid storage is strongly associated with the development of type 2 diabetes. Research during the last two decades has provided evidence for a role of lipid intermediates like diacylglycerol and ceramide in the induction of lipid-induced insulin resistance. However, recently novel data has been gathered that suggest that the relation between lipid intermediates and insulin resistance is less straightforward than has been previously suggested, and that there are several routes towards lipid-induced insulin resistance. For example, research in this field has shifted towards imbalances in lipid metabolism and lipid droplet dynamics. Next to imbalances in key lipogenic and lipolytic proteins, lipid droplet coat proteins appear to be essential for proper intramyocellular lipid storage, turnover and protection against lipid-induced insulin resistance.

Here, we discuss the current knowledge on lipid-induced insulin resistance in skeletal muscle with a focus on the evidence from human studies. Furthermore, we discuss the available data that provides supporting mechanistic information.
\end{abstract}

(c) 2011 Elsevier Ltd. All rights reserved.

\section{Contents}

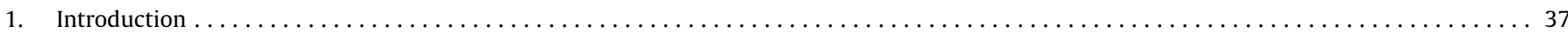

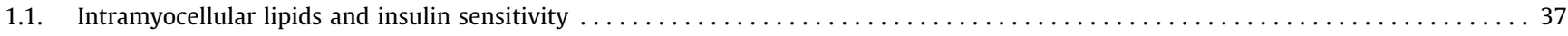

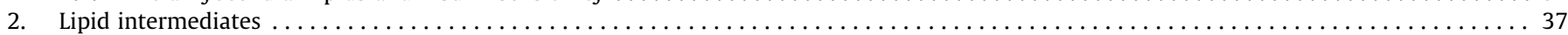

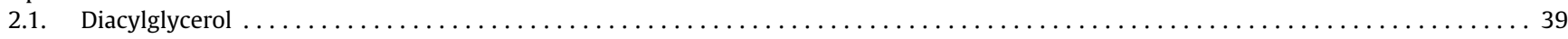

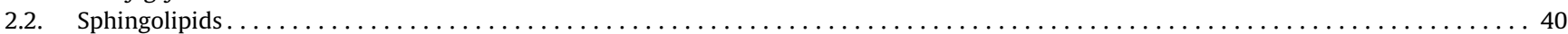

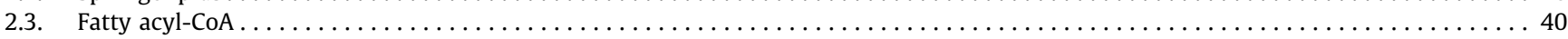

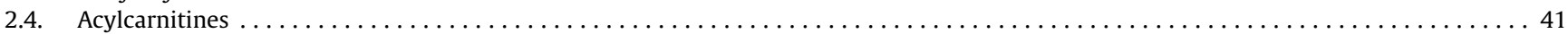

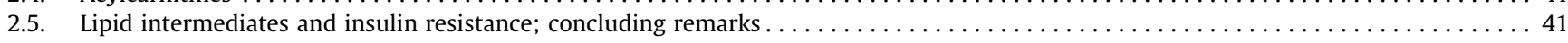

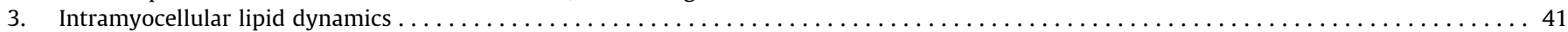

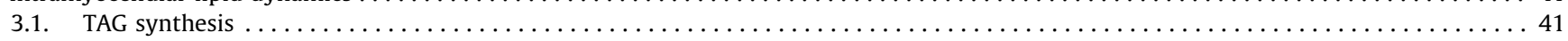

Abbreviations: ACS, acyl-CoA transferase; AcylCarn, acylcarnitines; ATGL, adipose triglyceride lipase; CPT1, carnitine palmitoyltransferase-1; DAG, diacylglycerol; DGAT, diacylglycerol acyltransferase; DGK, diacylglycerol kinase; EM, electron microscopy; FA, fatty acid; FFA, free fatty acid; GPAT, glycerol 3-phosphate acyltransferase; HSL, hormone-sensitive lipase; IMCL, intramyocellular lipids; IMTG, intramyocellular triacylglycerol; IRS-1, insulin receptor substrate 1; IS, insulin sensitivity; LCFA-CoA, long chain fatty acyl-CoA; LD, lipid droplet; MAG, monoacylglycerol; MGAT, monoacylglycerol acyltransferase; MGL, monoglyceride lipase; NGT, normal glucose tolerant; PA, phosphatidic acid; PFK1, phosphofructokinase-1; PKC, protein kinase C; PLIN, perilipin; PP2A, protein phosphatase 2A; SCD1, stearol-CoA desaturase-1; T2DM, type 2 diabetes mellitus; TAG, triacylglycerol; TCA, tricarboxylic acid cycle.

* Corresponding author. Tel.: +31 (0) 43 3881502; fax: +31 (0) 433670976.

E-mail address: p.schrauwen@maastrichtuniversity.nl (P. Schrauwen). 


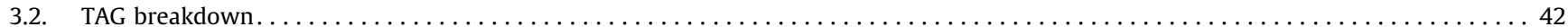

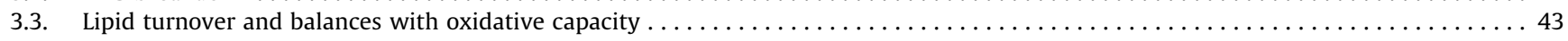

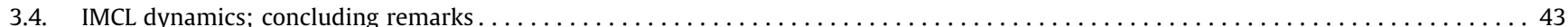

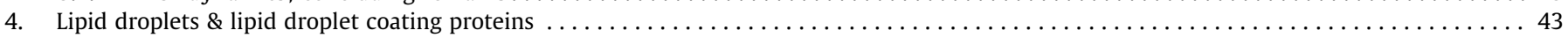

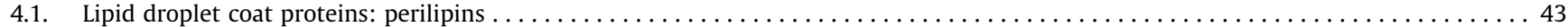

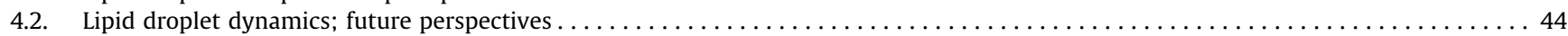

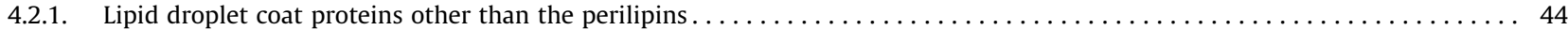

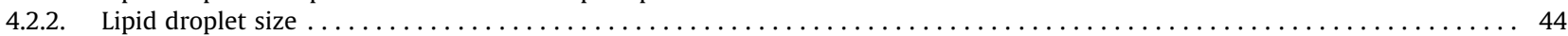

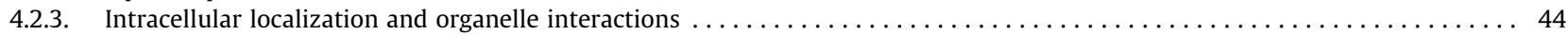

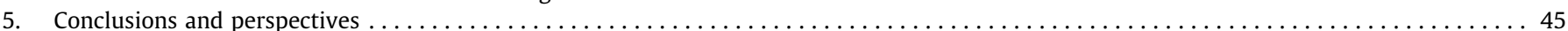

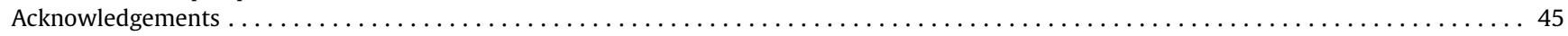

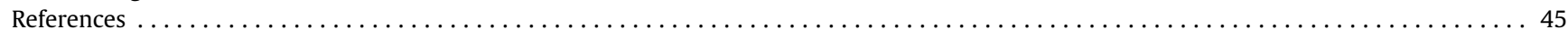

\section{Introduction}

Obesity is a growing public health problem, with a prevalence of at least 500 million people worldwide [1]. Although obesity will not always result in metabolic abnormalities, most severely obese persons suffer from metabolic comorbidities. Likewise, obesity is the number one risk factor for the development of insulin resistance, which may eventually result in type 2 diabetes. The etiology of type 2 diabetes is complex, with a broad range of organs involved. Several hypotheses have been put forward trying to explain the relationship between obesity and diabetes, including lipid, endocrine and inflammatory hypotheses [2]. In this review we will focus on the lipid overflow hypothesis, which considers type 2 diabetes to result from a general state of increased lipid levels. Lipids will overflow into the circulation as a result of impaired storage capacity in adipose tissue and as a consequence lipids may accumulate ectopically in tissues like skeletal muscle, liver and heart. The link between ectopic lipid accumulation in obesity and the development of insulin resistance was first demonstrated in the early nineties [reviewed in [3]] and had a great impact on our understanding of the etiology of type 2 diabetes. Since then, numerous animal and cellular experiments have provided evidence for the link between lipid intermediates and insulin resistance. On the other hand, data from human studies are less straightforward and have pointed towards multiple factors that may be involved in lipid-induced insulin resistance, including lipid intermediates, lipid metabolism and lipid droplet dynamics. Here we will review these data with a focus on human studies.

\subsection{Intramyocellular lipids and insulin sensitivity}

Obesity is associated with increased lipid supply to skeletal muscle. Intramyocellular lipid (IMCL) accumulation correlates with BMI, waist-to-hip ratio, central adiposity, and percentage body fat [4-8]. Skeletal muscle is quantitatively the major contributor to whole body insulin-mediated glucose disposal. Fat accumulation in muscle negatively impacts insulin mediated glucose uptake. In insulin resistant subjects, the negative correlation between IMCL accumulation and insulin sensitivity has been firmly established in multiple studies [9-11]. Furthermore, diet-induced weight loss results in decreased IMCL storage in parallel with improvements in insulin sensitivity [12-16]. Also, lipid infusion impairs insulin sensitivity concurrent with increased IMCL levels [17]. However, despite the strong correlation of IMCL levels with insulin resistance, the exact mechanistic link between IMCL accumulation and impairment of insulin sensitivity is unclear. Furthermore, IMCL levels are similar in obese normoglycemic and obese type 2 diabetic subjects $[18,19]$, indicating that total IMCL levels per se do not induce diabetes.

An important finding that has shed some light into the role of IMCL in insulin resistance comes from exercise studies. Exercise training has been shown to increase IMCL levels, and endurancetrained athletes, who are highly insulin-sensitive, have increased IMCL compared with lean sedentary controls, with levels even exceeding those of diabetics [18,20]. In addition, 12-16 weeks of exercise training in obese subjects improved insulin sensitivity in conjunction with increased IMCL levels $[21,22]$. This so-called athlete's paradox gave new insight in the role of IMCL in insulin resistance and indicated that IMCL accumulation per se does not lead to insulin resistance. The athlete's paradox has been explained by differential effects of training and diabetes on lipid subspecies, oxidative capacity and IMCL turnover. Proper balancing between lipid influx and fat oxidative capacity as well as an efficient rate of lipid turnover (i.e. lipid depletion and efficient resynthesis) have been suggested to be beneficial for insulin sensitivity $[18,20]$. It is still unclear, however, how IMCL can become harmful. In this review, we will discuss the current knowledge on lipid-induced insulin resistance in skeletal muscle with a focus on the evidence from human studies, combined with supporting information of the mechanisms involved from animal and cell studies.

\section{Lipid intermediates}

It was demonstrated in multiple studies that intramyocellular lipid levels are increased in obese type 2 diabetics versus lean controls [9-11]. The observation that IMCL storage is increased in athletes and mainly consists of intramyocellular triacylglycerol (TAG) [23] strongly indicated that neutral lipid storage in the form of TAG per se does not impair insulin sensitivity. However, increased intramyocellular TAG might be paralleled with increased levels of lipid intermediates with lipotoxic potential. Lipotoxicity is defined as the accumulation of excess lipids in non-adipose tissues leading to cell dysfunction or cell death [24]. Enhancing the partitioning of fatty acids (FAs) entering the muscle towards TAG synthesis prevents lipotoxicity [25,26]. Under conditions of increased lipid influx, lack of TAG storage capacity, or uncontrolled lipolysis, FAs might be converted to lipid metabolites other than TAG.

The array of lipid intermediates with insulin desensitizing properties includes diacylglycerols (DAGs), long chain fatty acyl-CoAs (LCFA-CoAs), acylcarnitines, and ceramides (Fig. 1) all differing in chain length, level of saturation and/ or stereo specificity. At this moment there is a lack of consensus on the primary lipotoxic intermediate. These intermediates all have the potential to reduce insulin-mediated glucose disposal in in vitro and animals studies, partly via selective interference with insulin signaling. However, most if not all available data from in vitro and animal studies are merely correlative, as it is impossible to alter intracellular levels of one single lipotoxic intermediate. Therefore, interpretation of causality is difficult, especially with regard to their implication in obesityassociated insulin resistance in humans. Most attention has been given to DAG and ceramide. Table 1 gives an overview of the human studies in which DAG and/or ceramides were measured 


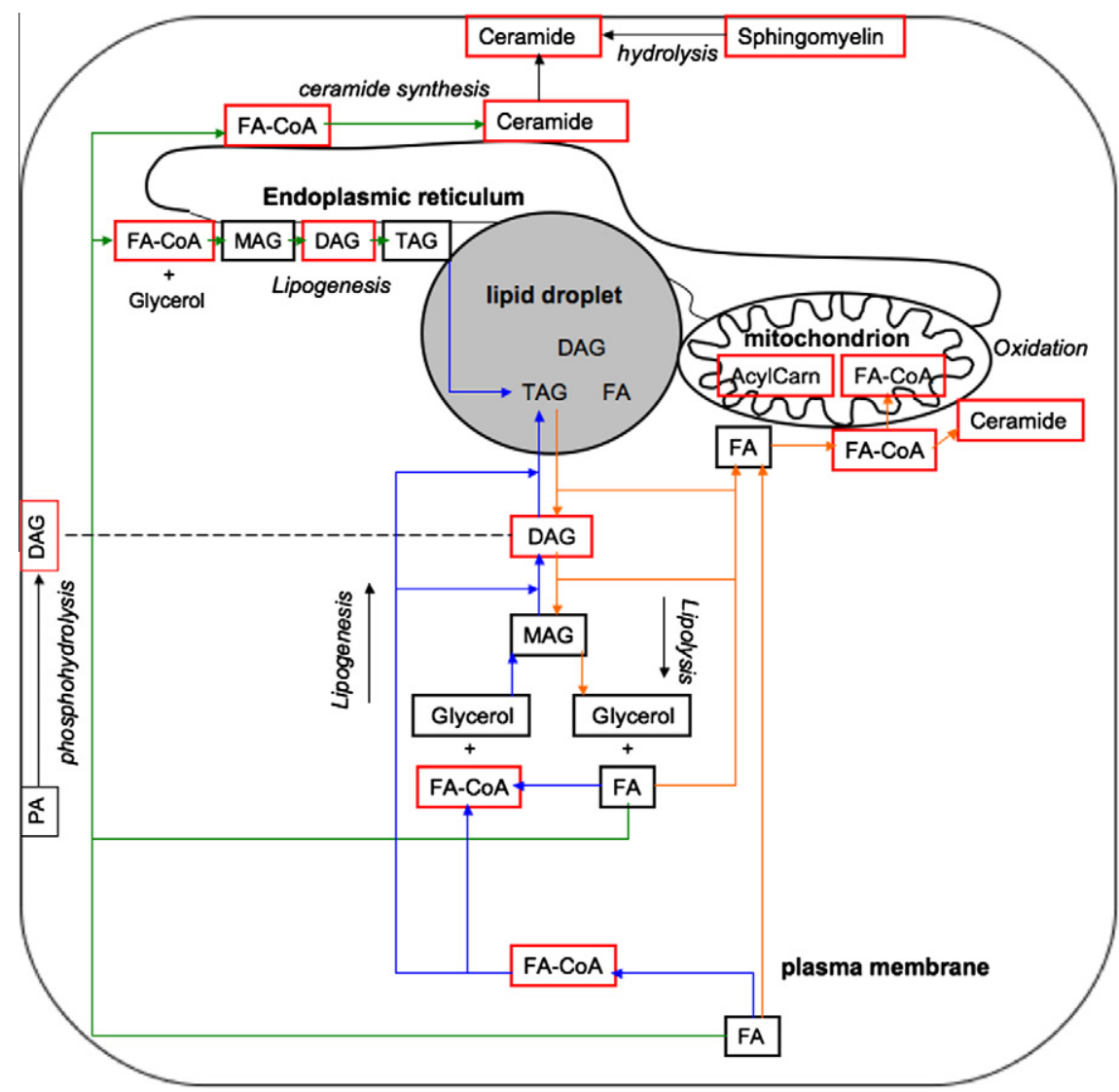

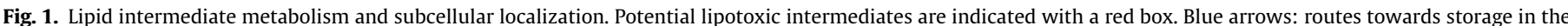

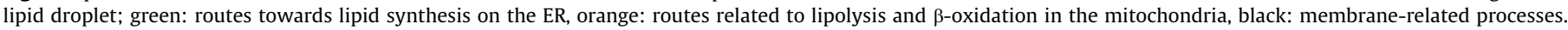
AcylCarn: acylcarnitines, DAG: diacylglycerol, FA: fatty acid, FA-CoA: fatty acyl-CoA, MAG: monoacylglycerol, PA: phosphatidic acid, TAG: triacylglycerol.

Table 1

Lipid intermediates in lean, obese and T2DM subjects.

\begin{tabular}{|c|c|c|c|c|}
\hline $\begin{array}{l}\text { Author and } \\
\text { reference }\end{array}$ & Population & $\begin{array}{l}\text { Association } \\
\text { DAG with } \\
\text { insulin } \\
\text { sensitivity }\end{array}$ & $\begin{array}{l}\text { Association } \\
\text { ceramides with } \\
\text { insulin } \\
\text { sensitivity }\end{array}$ & Outcomes \\
\hline $\begin{array}{l}\text { Van Hees } \\
\text { et al. [52] }\end{array}$ & $\begin{array}{l}30 \text { male subjects with the metabolic syndrome, } 15 \\
\text { insulin resistant subjects and } 15 \text { controls }\end{array}$ & - & n.i. & $\begin{array}{l}\text { Increased saturation of DAG is associated with insulin } \\
\text { resistance }\end{array}$ \\
\hline $\begin{array}{l}\text { Perreault } \\
\quad \text { et al. [47] }\end{array}$ & $\begin{array}{l}\text { Obese NGT ( } n=7 \text { men and } n=12 \text { women) and } \\
\text { prediabetics ( } n=13 \text { men and } n=7 \text { women) }\end{array}$ & - & n.i. & $\begin{array}{l}\text { Turnover of DAG is more important than the DAG level, } \\
\text { DAG level the same in NGT and prediabetics }\end{array}$ \\
\hline $\begin{array}{l}\text { Jocken et al. } \\
\qquad[42]\end{array}$ & $\begin{array}{l}\text { Lean }(n=13) \text { and obese }(n=10) \text { men (study } 1) \text { and } \\
\text { nonobese T2D }(n=11) \text {, obese T2D }(n=11) \text {, and } \\
\text { lean male controls }(n=11) \text { (study } 2)\end{array}$ & - & n.i. & Lower DAG in obese men versus lean controls \\
\hline $\begin{array}{l}\text { Coen et al. } \\
\text { [45] }\end{array}$ & $\begin{array}{l}\text { Insulin sensitive }(n=10) \text { and insulin resistant } \\
(n=12) \text { obese women }\end{array}$ & - & + & $\begin{array}{l}\text { No difference in DAG, increased ceramides in insulin } \\
\text { resistance }\end{array}$ \\
\hline $\begin{array}{l}\text { Bergman } \\
\text { et al. [23] }\end{array}$ & $\begin{array}{l}\text { Endurance-trained male athletes }(n=11) \text { and } \\
\text { sedentary male controls }(n=11)\end{array}$ & + & n.i. & $\begin{array}{l}\text { Saturation of DAG is of importance, no differences in total } \\
\text { DAG }\end{array}$ \\
\hline $\begin{array}{l}\text { Thrush et al. } \\
\text { [43] }\end{array}$ & Lean $(n=8)$ and obese $(n=15)$ women & - & + & No role for DAG, ceramides increased in obese \\
\hline $\begin{array}{l}\text { Moro et al. } \\
\quad[7]\end{array}$ & 48 subjects with a wide range of BMI (m/f: 24/24) & + & + & $\begin{array}{l}\text { Increased DAG and ceramides in obese and type } 2 \text { diabetic } \\
\text { subjects. DAG is the main predictor for insulin resistance, } \\
\text { lipolytic enzymes determine DAG levels }\end{array}$ \\
\hline $\begin{array}{l}\text { Anastasiou } \\
\text { et al. [44] }\end{array}$ & $\begin{array}{l}\text { Nondiabetic obese }(n=19 \text {, male/female: } 9 / 10) \text { and } \\
\text { diabetic obese }(n=11, \mathrm{~m} / \mathrm{f}: 2 / 9)\end{array}$ & - & n.i. & No role for DAG \\
\hline $\begin{array}{l}\text { Skovbro et al. } \\
\text { [67] }\end{array}$ & $\begin{array}{l}\text { Type } 2 \text { diabetics }(n=8) \text {, IGT }(n=9) \text {, healthy } \\
\text { controls }(n=8) \text {, endurance-trained athletes }(n=8) \\
\text { (all male subjects) }\end{array}$ & n.i. & - & No role for ceramides \\
\hline $\begin{array}{l}\text { Serlie et al. } \\
\quad[66]\end{array}$ & $\begin{array}{l}\text { Lean }(n=8, \mathrm{~m} / \mathrm{f}: 7 / 1) \text { and obese }(n=6, \mathrm{~m} / \mathrm{f}: 4 / 2) \\
\text { subjects }\end{array}$ & n.i. & - & No difference in ceramides \\
\hline $\begin{array}{l}\text { Straczkowski } \\
\text { et al. [41] }\end{array}$ & $\begin{array}{l}\text { Male lean, obese, type } 2 \text { diabetics and offspring of } \\
\text { type } 2 \text { diabetics ( } n=12 \text { per group) }\end{array}$ & + & + & $\begin{array}{l}\text { DAG and ceramides independently determine insulin } \\
\text { resistance }\end{array}$ \\
\hline $\begin{array}{l}\text { Adams et al. } \\
\text { [65] }\end{array}$ & $\begin{array}{l}\text { Obese insulin resistant }(n=10, \mathrm{~m} / \mathrm{f}: 5 / 5) \text { and lean } \\
\text { controls }(n=10, \mathrm{~m} / \mathrm{f}: 6 / 4)\end{array}$ & n.i. & + & Increased ceramides in obese insulin resistant subjects \\
\hline
\end{tabular}

n.i. = Not investigated, m/f: male/female ratio. 
in skeletal muscle biopsies of obese, type 2 diabetic and/or lean controls.

\subsection{Diacylglycerol}

DAG is an intermediate in TAG synthesis and breakdown. In addition, DAG and its metabolite phosphatidic acid (PA) are important intracellular second messengers involved in metabolic and mitogenic responses and are important metabolites in de novo synthesis of phospholipids $[27,28]$. Hence, fluctuations in DAG levels can lead to impaired intracellular signaling. Animal and cell studies have sought to unravel the mechanisms involved in DAG-induced insulin resistance [29,30]. In muscle, elevated DAG levels are associated with increased activities of PKC $\theta$ and PKC 8 [31,32]. DAGactivated PKCs inactivate insulin receptor substrate 1 (IRS-1) by phosphorylation of one or more of its inhibitory serine residues and by direct association of PKC $\varepsilon$ with IRS-1, thereby reducing its kinase activity. Through this mechanism, DAG reduces insulininduced tyrosine phosphorylation of IRS- 1 and suppressing the activity of its downstream targets PI3-kinase and PKB/Akt, leading to impaired insulin-induced GLUT4-translocation and glucose uptake [reviewed in [33]]. Several DAG-subspecies exist that differ in FA composition and the position of the FA on the glycerol backbone (1,3-DAG, 2,3-DAG, and 1,2-DAG). Only 1,2-DAG accumulates in membranes and is capable of activating PKCs [34-36], 2,3-DAG and 1,3-DAG can arise from TAG hydrolysis at the lipid droplet.

Intramuscular DAG levels are increased in several animal models of obesity $[37,38]$. However, evidence is lacking on the importance of intramyocellular DAG levels in the development of obesity-associated insulin resistance in humans. Although lipid infusion in humans induces insulin resistance in parallel with increased intramyocellular DAG levels [39], the support for a role of skeletal muscle DAG accumulation in the development of type 2 diabetes is inconsistent (Table 1 ). Two studies identified the DAG level as an important predictor for insulin resistance using multivariate regression analyses $[40,41]$. However, the remainder of the studies did not find differences in total skeletal muscle DAG levels between obese and lean subjects $[42,43]$ and between obese normal glucose tolerant (NGT) and obese insulin resistant subjects [44-46]. Perreault et al. showed inter-gender differences in intramuscular DAG accumulation, with prediabetic women having higher DAG levels, while being more insulin sensitive compared with prediabetic men [47]. Strategies that resulted in improved insulin sensitivity did not consistently reduce DAG levels, which indicates that the role of DAG in insulin resistance in humans is not yet clear. DAG levels decreased with weight loss and exercise in several studies $[21,48,49]$ (Table 2 ), while pioglitazone treatment [50] and 10\% diet-induced weight loss [51] did not show a decrease in DAG levels. Moreover, while Dubé et al. showed that total intramyocellular DAG decreased with weight loss and exercise, there was no correlation between changes in DAG and improvements in insulin sensitivity suggesting that DAG is not the sole mediator of insulin action [49].

Based on the data summarized above, it can be concluded that total DAG levels do not necessarily mirror insulin resistance. Recent evidence suggests that it is not total DAG per se but rather specific DAG-subspecies that may be important. In the study of Dubé et al. [49], it was shown that exercise caused greater reductions in specific FAs in the DAG fraction compared to diet-induced weight loss [49]. Exercise lowered the content of all DAG species examined to a greater degree than diet-induced weight loss, which only reduced the content of all DAG C14:0 species, and of DAG C16:0/18:0, C16:0/ 18:1, C16:1/18:1, di-C16:0 and di-C18:1 [49]. Moreover, it was demonstrated that athletes have a lower saturation of the DAG-fraction compared to sedentary controls or an increased proportion of C18:1 and C18:2 in the DAG fraction [23]. Recently, Van Hees et al. investigated the FA composition of intramyocellular DAG and TAG in men with the metabolic syndrome, either with or without insulin resistance. While total DAG and TAG levels were similar in both groups, insulin resistant men had a higher degree of saturation of skeletal muscle DAG compared to controls [52], consistent with the study of Bergman et al. [23]. This higher degree of saturation

Table 2

Interventions.

\begin{tabular}{|c|c|c|c|c|}
\hline Author and reference & Population and intervention & $\begin{array}{l}\text { Association } \\
\text { DAG with IS }\end{array}$ & $\begin{array}{l}\text { Association } \\
\text { ceramides } \\
\text { with IS }\end{array}$ & Outcomes \\
\hline Dubé et al. [49] & $\begin{array}{l}\text { Male }(n=7) \text { and female }(n=9) \text { overweight (IGT and } \\
\text { NGT) subjects, } 16 \text { week diet or exercise intervention } \\
\text { ( } n=8 \text { per group) }\end{array}$ & + & + & $\begin{array}{l}\text { No correlation of changes in DAG and ceramides and } \\
\text { improvements in insulin sensitivity. Differences in DAG and } \\
\text { ceramide subspecies. Ceramides decreased only with the } \\
\text { exercise training }\end{array}$ \\
\hline Hoeg et al. [69] & $\begin{array}{l}\text { Young healthy men }(n=8) \text { and women }(n=8) \text {, lipid } \\
\text { infusion-induced insulin resistance }\end{array}$ & - & - & $\begin{array}{l}\text { Intralipid infusion did not lead to accumulation of DAG or } \\
\text { ceramides, while inducing insulin resistance }\end{array}$ \\
\hline Anastasiou et al. [51] & A weight loss program in obese women $(n=5)$ & - & n.i. & TAG was depleted upon weight loss, DAG was unchanged \\
\hline Bajaj et al. [50] & $\begin{array}{l}\text { Pioglitazone treatment in diabetics }(n=24 \text {; both } \\
\text { male and female) }\end{array}$ & - & n.i. & $\begin{array}{l}\text { FA-CoA was decreased and associated with improvements in } \\
\text { insulin sensitivity, no differences in DAG }\end{array}$ \\
\hline Dubé et al. [21] & $\begin{array}{l}\text { Exercise program in obese men }(n=9) \text { and women } \\
(n=16)\end{array}$ & + & + & $\begin{array}{l}\text { Decreased DAG and ceramides after the exercise intervention } \\
\text { period }\end{array}$ \\
\hline Vistisen et al. [71] & $\begin{array}{l}\text { Obese women and men ( } n=8 \text { per group), lipid } \\
\text { infusion-induced insulin resistance }\end{array}$ & - & - & $\begin{array}{l}\text { The lipid-induced inhibition of glucose disposal is similar in } \\
\text { obese females and males. DAG and ceramides were similar } \\
\text { between sexes }\end{array}$ \\
\hline Schenk et al. [72] & $\begin{array}{l}\text { Acute exercise in non-obese women }(n=8) \text {, } \\
\text { followed by an overnight lipid infusion-induced } \\
\text { insulin resistance }\end{array}$ & + & + & $\begin{array}{l}1 \text { exercise session completely reversed FA-induced insulin } \\
\text { resistance, decreased DAG and ceramides }\end{array}$ \\
\hline Serlie et al. [66] & $\begin{array}{l}\text { Lean ( } n=8 \text {, both sexes) and obese }(n=6) \text { subjects, } \\
\text { lipid infusion and Acipimox treatment }(6 \mathrm{~h})\end{array}$ & n.i. & - & $\begin{array}{l}\text { No differences in ceramides at baseline and no differences } \\
\text { after } 6 \text { h lipid infusion or Acipimox treatment }\end{array}$ \\
\hline Bruce et al. [48] & $\begin{array}{l}\text { Exercise intervention with obese subjects ( } n=9 \text {; } \\
\text { both sexes) }\end{array}$ & + & + & $\begin{array}{l}\text { Exercise decreases ceramides and DAG, in parallel with } \\
\text { improved IS }\end{array}$ \\
\hline Straczkowski et al. [70] & $\begin{array}{l}\text { Healthy male subjects }(n=10) \text {, lipid infusion- } \\
\text { induced insulin resistance }\end{array}$ & n.i. & + & $\begin{array}{l}\text { A } 4 \mathrm{~h} \text { intralipid infusion increased ceramide levels concurrent } \\
\text { with the induction of insulin resistance }\end{array}$ \\
\hline Itani et al. [39] & $\begin{array}{l}\text { Healthy male subjects }(n=12) \text {, lipid infusion- } \\
\text { induced insulin resistance }\end{array}$ & + & - & $\begin{array}{l}\text { Increased DAG levels with lipid-induced insulin resistance, } \\
\text { no changes in ceramides }\end{array}$ \\
\hline
\end{tabular}


was largely explained by a higher percentage of palmitic acid and a lower percentage of oleic acid [52].

Next to differences in FA-composition, DAG-subspecies can differ in the position of the FA-binding to the glycerol backbone (1,3-DAG, 2,3-DAG, and 1,2-DAG). 1,2-DAG accumulates in membranes and only this isoform is capable of activating PKCs [36]. No human study performed to date has examined specifically the accumulation of 1,3-, 2,3- and 1,2-DAG in insulin resistant and insulin sensitive subjects. Moreover, the fact that DAG can be present at different subcellular locations, including cell membranes, ER and lipid droplets (LDs) [53], may complicate the relationship between DAG levels and insulin resistance. The DAG membraneto-cytosol ratio has been used as a measure for DAG-induced PKC activation [54-56], but data from human studies is lacking.

In summary, total DAG levels are not consistently associated with insulin resistance in humans. While it is apparent that increased DAG levels per se do not promote insulin resistance, lipid-induced insulin resistance may be dependent on the accumulation of bioactive DAG species at specific intracellular sites, including the plasma membrane for PKC-mediated interferences with insulin signaling. However, few data are available in humans and further research is needed to investigate the relationship between various DAG species and their intracellular localization, and insulin resistance in skeletal muscle.

\subsection{Sphingolipids}

Another group of lipid intermediates that has received a lot of attention are the ceramides, which belong to the sphingolipids. Ceramides are structural components of biological membranes and can be deacetylated, phosphorylated and glycosylated [reviewed in 57]. Ceramides are important membrane building blocks and intracellular messengers that are believed to interfere with insulin signaling. Sphingolipid production mainly depends on de novo biosynthesis. In as much as long chain saturated FAs like palmitate are precursors for ceramide synthesis, rates of ceramide synthesis depend on the availability of those FAs. Consistent with this notion, incubation of muscle cells with palmitate promotes ceramide accumulation [29] and diets high in saturated fats induce intramyocellular ceramide accumulation [58]. In addition to FAs serving as precursors for ceramide synthesis, FAs, inflammatory agonists and glucocorticoids have been shown to increase ceramide biosynthesis via upregulation of serine palmitoyltransferase, the limiting enzyme for ceramide synthesis [57,59-61]. Evidence abounds that accumulation of ceramides can impair insulin signaling (reviewed in [57]). Indeed, ceramide was identified as an essential intermediate linking saturated FAs to insulin resistance [62]. According to some reports, ceramides inactivate IRS-1, leading to blockage of PI3-kinase. However, the majority of studies suggest that ceramide inhibits phosphorylation and activation of $\mathrm{Akt} / \mathrm{PKB}$ via protein phosphatase $2 \mathrm{~A}$ (PP2A) and $\mathrm{PKC} \zeta$, independent of potential effects on IRS-1 [reviewed in 57]. Additionally, glycosylceramides have been shown to interact with the insulin receptor, thereby displacing it from the caveola thus preventing downstream signaling [63]. Interestingly, Novgorodov et al. recently showed that next to ER-derived ceramide, ceramides are also produced in mitochondria by the coupled activities of mitochondrial thioesterase, which hydrolyses palmitoyl-CoA to CoA and palmitate, and neutral ceramidase (NCDase), which utilizes sphingosine and released palmitate in a reverse reaction to produce ceramide [64]. Thus, increased FA-CoA levels in or near the mitochondria might result in increased ceramide production thus impairing mitochondrial function and eventually inducing apoptosis [64].

Inhibition of ceramide synthesis was shown to improve insulin sensitivity in rodents [59]. Consistent with a role for ceramide in insulin resistance in humans, the majority of human studies found increased ceramide levels in skeletal muscle of type 2 diabetic subjects (Table 1). Most $[7,41,43,65]$, but not all [66,67] studies observed increased accumulation of ceramides in skeletal muscle of obese subjects compared to lean controls. Furthermore, ceramides were shown to be higher in insulin resistant obese subjects compared to insulin sensitive obese subjects [41,45], indicating a potential role of ceramides in insulin resistance. Two reports did not show increased ceramides in obese IGT [66] and obese diabetics versus lean controls [67]. Moro et al. found increased ceramides in T2DM, but identified DAG as the key mediator of lipid-induced insulin resistance based on multivariate stepwise regression analyses [7]. Interestingly, acute and chronic exercise interventions have been shown to decrease ceramide levels $[48,68]$ (Table 2). As the sphingolipid family consists of a range of different subspecies (different ceramides and non-ceramide sphingolipids), (total) ceramide levels might not reflect levels of bioactive sphingolipid subspecies appropriately. Likewise, saturated ceramides were shown to be increased in obese compared to lean subjects $[7,43,65]$ and type 2 diabetes patients versus NGT BMI-matched controls [45]. Furthermore, Dubé et al. showed that dihydroceramides increased with both dietinduced weight loss and exercise training, whereas sphingosines and total ceramide species were decreased with exercise, while only C14:0, C20:0 and C24:0 ceramides were decreased with diet-induced weight loss [49], indicating that certain bioactive ceramide subspecies, rather than total ceramide levels, may be causative in obesity-associated insulin resistance.

Several studies investigated the effects of lipid infusion-induced insulin resistance on the accumulation of ceramides in skeletal muscle [39,66,69-71]. A 4-6 h lipid infusion (intralipid) in four out of five studies did not result in increased levels of ceramides, despite inducing insulin resistance $[39,66,69,71]$. Only Straczkowski et al. did observe increased ceramide levels [70]. However, as intralipid mainly consists of unsaturated fats (20\% triglyceride emulsion, generally safflower- and soy-oil), ceramides might not play a main role in acute lipid-infusion mediated insulin resistance. Holland et al. tested this hypothesis of different fatty acids inducing insulin resistance in muscle via distinct mechanisms by infusing either a lard-oil based solution (mainly saturated fats) versus a soy-based cocktail (mainly unsaturated fats) into rats [59]. Indeed, while both lipid infusions resulted in insulin resistance, only the lard-oil infusion induced ceramide accumulation. Thus, ceramide accumulation may be involved in saturated fat-induced but not intralipid-induced insulin resistance in human skeletal muscle. Further investigation into sphingolipid subspecies and their intracellular localization could provide more information on the mechanisms involved.

\subsection{Fatty acyl-CoA}

Lipid intermediates that have received less attention so far are fatty acyl-CoAs and acylcarnitines. Upon entry into muscle cell either by diffusion or FA-transporters, fatty acids are trapped within the cell after a CoA group is bound by acyl-CoA synthetase. If fatty acid uptake exceeds the capacity for fatty acid channeling towards lipid synthesis or $\beta$-oxidation, FA-CoA will accumulate in the cell, either in the cytosol or in mitochondria. Indeed, rats fed a high fat diet showed an increased accumulation of long chain FA-CoAs (LCCoAs) in skeletal muscle [72]. Currently, the importance of FA-CoA in insulin resistance remains unclear. In a number of human studies, LC-CoA levels, like other lipid intermediates, were observed to be elevated in insulin resistant muscle. LC-CoA levels were increased in skeletal muscle biopsies from obese subjects [73] and correlated negatively with whole body insulin action (i.e. glucose infusion rates during a hyperinsulinemic euglycemic clamp) [72]. Furthermore, LC-CoA levels were increased upon short-term (4-6 h) lipid infusion in parallel with PKC-mediated inhibition of insulin signaling [74,75] and insulin-sensitizing strategies were described to lower intramus- 
cular LC-CoA levels $[50,76,77]$. In contrast, in the study of Bruce et al., both basal and insulin-stimulated skeletal muscle LC-CoA content were similar between young trained, young sedentary subjects, type 2 diabetics and obese controls [78].

It is unclear whether FA-CoAs as such are interfering with the insulin signaling cascade. There are indications for PKC activation by FA-CoA, but it is unclear whether this is a direct or an indirect effect (via DAG) [reviewed in [79]]. Next to being substrates for TAG synthesis and energy production, FA-CoAs are used as substrates for protein acylation reactions. Interestingly, Jenkins et al. recently showed that LC-CoA is capable of inhibiting phosphofructokinase-1 (PFK1) activity by reversible acylation, resulting in a lowered glycolytic flux under high intracellular ATP conditions [80]. Intracellular accumulation of LC-CoA may thus inhibit glycolysis downstream of insulin signaling, without affecting non-oxidative glucose disposal [80]. LC-CoAs are also substrates for synthesis of phospholipids, TAG, DAG and ceramides. Hence, accumulation of LC-CoAs can lead to increased formation of lipid intermediates with the potential to impair insulin signaling. Additionally, intramitochondrial accumulation of acyl-CoAs, as a result of a disbalance in mitochondrial FA transport and downstream oxidative metabolism, and their metabolites ceramides [64] and acylcarnitines [81] might contribute to mitochondrial failure. Based on available evidence, it is too early to draw conclusions about the importance of FA-CoA in the etiology of insulin resistance in skeletal muscle. Information on intracellular localization and verification of its inhibitory effects on glucose metabolism is warranted.

\subsection{Acylcarnitines}

Upon entrance into the mitochondria, FA-CoAs are degraded during $\beta$-oxidation, which yields one acetyl-CoA molecule in each successive cycle. When $\beta$-oxidation rates outpace the capacity of the TCA cycle, CRAT lowers short-chain acetyl-CoA levels by coupling of a carnitine moiety thus producing acylcarnitines. CPT2, present in the inner-mitochondrial membrane, is best known for its capacity to convert acylcarnitines to carnitine plus FA-CoA. However, CPT2 has a dual role; the enzyme can operate in the reverse direction generating medium and long-chain acylcarnitines produced from intramitochondrial acyl-CoAs and transporting those to the cytoplasm [82]. A sustained mitochondrial FA oversupply and incomplete fatty acid oxidation therefore results in mitochondrial accumulation of FA-CoAs and acylcarnitines. In contrast to FA-CoAs, acylcarnitines can cross membranes and end up in the cytoplasm or in the blood.

Incomplete FA oxidation resulting in intramyocellular accumulation of (C6 to C22)-acylcarnitines and other intermediates has been demonstrated to be increased in obesity [83-86]. Furthermore, blood plasma acylcarnitine levels were increased in obese subjects compared to lean controls $[87,88]$ and in type 2 diabetes patients compared to BMI-matched controls [89,90]. Additionally, exercise training improved rates of complete $\beta$-oxidation in parallel with improved insulin sensitivity in mice [91] and in obese humans subjected to caloric restriction [92]. It was therefore suggested that mitochondria are very vulnerable to substrate overloads and therefore might serve as the principal lipid sensor in skeletal muscle [81]. In contrast, Boyle et al. observed lower levels of short and medium chain acylcarnitines in obese compared to lean subjects, long chain acylcarnitines were similar [84]. Interestingly though, following a 5 day high fat diet the obese subjects showed increased short and medium chain acylcarnitines compared to the lean controls [84].

The association of acylcarnitine levels with insulin resistance is based on observational studies and might be a reflection of lipid overload rather than that acylcarnitines are causative in lipidinduced impairments in insulin signaling. Further research is warranted to identify the importance of mitochondrial acylcarnitine species in insulin resistance.

\subsection{Lipid intermediates and insulin resistance; concluding remarks}

Taken together, human studies are far from consistent with regard to lipid intermediate accumulation in skeletal muscle of type 2 diabetes patients. The inconsistencies in the study outcomes could be explained by differences in analytical tools, differences in the timing of the biopsies, age of the subjects, inter-gender variation $[47,69]$, and inter-individual (genetic) variation. Ceramides, acyl-CoAs and DAG have the potential to interfere with insulin signaling. The prevailing importance of one over the other may well be related to specific (experimental) circumstances. For example, lipid infusion-induced insulin resistance seems to be predominantly associated with increased DAG levels, whereas ceramides are mainly associated with saturated fat intake. It deserves mention though, that although lipid infusion is often used to mimic lipid-induced insulin resistance, it is questionable whether the effects of the supraphysiological plasma FFA levels due to a short-term infusion of a lipid mixture reflect the mechanisms involved in obesity-induced insulin resistance.

Exercise interventions generally decrease both intramyocellular DAG and ceramide levels. Acylcarnitine levels seem to be important indicators of substrate overload, but evidence for a role in lipid-induced insulin resistance is limited. Support for a role of FA-CoA on insulin signaling is most limited, but is also the least examined option. Nevertheless, FA-CoA accumulation may well be involved in blunting oxidative glucose disposal by inhibiting glycolysis without an effect on non-oxidative glucose disposal. However, in general total skeletal muscle DAG, ceramide or FA-CoA levels are not consistently elevated in insulin resistant subjects. It is therefore questionable whether one of these lipid intermediates has a causal role in obesity-associated insulin resistance. However, given the lipotoxic potential of these lipid intermediates, it is likely that there are several routes towards lipid-induced insulin resistance. Further specification of the lipotoxic intermediates by (de)saturation $[7,23,48,93]$, chain length $[45,49]$, stereo specific isomers, and intracellular localization could give further insight into the lipotoxic mechanisms involved in the development of type 2 diabetes in obese subjects.

\section{Intramyocellular lipid dynamics}

Although research in the last decades has focused primarily on levels of lipid intermediates to explain muscular insulin resistance, more recent data also suggest that intramyocellular lipid dynamics may play an important role in regulating insulin sensitivity. Next to alterations in myocellular lipid influx, an altered rate of lipid turnover, either a decreased triglyceride synthesis, or increased lipolysis (not matched by increased fatty acid oxidation), and reductions in oxidative capacity have been suggested to be the underlying causes for lipid-induced insulin resistance.

\subsection{TAG synthesis}

Upon entrance of fatty acids into the muscle cell, fatty acids can be incorporated into IMCL for storage and/or can be directed to mitochondria for oxidation. One hypothesis explaining the athlete's paradox says that as long as fatty acids are efficiently directed towards storage as TAG, there is no interference with insulin signaling. Based on this notion it could be argued that the expression of enzymes involved in lipid synthesis may be an important determinant of obesity-induced insulin resistance.

Initiation of lipid synthesis requires coupling of fatty acids to a glycerol backbone. Glycerol 3-phosphate acyltransferase (GPAT) 
and diacylglycerol acyltransferase (DGAT) are important rate limiting enzymes in this process. Multiple acyltransferase isoforms exist, including GPATs 1-4 and DGAT1 and DGAT2. GPATs 1 and 2 are present in the outer mitochondrial membrane, GPATs 3 and 4 localize to the ER [reviewed in [94]]. At least $90 \%$ of the GPAT activity in skeletal muscle is contributed by GPAT1 [95]. DGAT1 resides in the ER [96], whereas DGAT2 localizes to ER, mitochondria and lipid droplets [53,97,98]. Both DGAT1 and DGAT2 are present in skeletal muscle $[99,100]$, but DGAT1 is the predominant skeletal muscle DGAT isoform [99]. Little is known about the expression of glyceride synthesis enzymes in human skeletal muscle of healthy, obese and diabetic subjects. Two reports on lipogenic enzyme expression in skeletal muscle of obese subjects failed to find differences in skeletal muscle GPAT and DGAT1 protein expression between lean and obese subjects $[43,101]$. On the other hand, acute exercise increased GPAT and DGAT1 protein expression while preventing lipid-induced insulin resistance [102]. GPAT and DGAT1 protein expression levels are dynamic, albeit only in the short-term. Eight [103] or sixteen weeks [49] of aerobic exercise or diet-induced weight loss [49], conditions associated with an increase and a decrease in intramyocellular TAG levels respectively, did not alter DGAT1 expression in obese subjects, indicating that at least DGAT1 mRNA and protein expression levels are not major determinants of IMCL levels in human skeletal muscle. Moreover, DGAT1 mRNA expression is similar in endurance-trained athletes and sedentary controls [104] and a lipid infusion following one exercise session increased GPAT activity without affecting DGAT activity [105]. In contrast to the limited evidence from human studies, animal studies showed beneficial effects of DGAT1 overexpression on insulin sensitivity $[25,26,106]$. We showed that a short-term (1 week) overexpression of DGAT1 in the tibialis anterior muscle of rats increased both TAG and DAG levels indicating that increasing lipid turnover by means of DGAT1 overexpression protects against insulin resistance [26].

Another enzyme that has received interest in the synthesis of TAG in muscle is SCD1. SCD1 is a member of the family of stearoylCoA desaturases (SCDs). Four isoforms exist in mice (SCD1-4) and two isoforms in humans (SCD1 and SCD5) [reviewed in [107]]. Both SCD1 and SCD5 localize to the ER [108]. SCD1 and SCD5 desaturate fatty acids at the delta 9 position [108]. Little is known about the function of SCD5. SCD1 is predominantly expressed in liver, adipose tissue and skeletal muscle [107] and functions as a rate-limiting enzyme in the biosynthesis of monounsaturated fatty acids; it desaturates stearate and palmitate to generate the less toxic monounsaturated FAs oleate and palmitoleate. Unsaturated FAs are the preferred substrates for TAG synthesis. SCD1 is upregulated with exercise training $[23,49,109]$ and protects against saturated fatinduced insulin resistance in myotubes in vitro [110,111]. On the other hand, SCD1 protein expression was similar in obese and lean subjects in the study of Thrush et al. [43] and was even shown to be increased in severely obese subjects the study of Hulver et al. [112]. Nevertheless, the beneficial effects of DGAT1 and SCD1 overexpression further support the notion that channeling FAs to TAG synthesis is beneficial for insulin sensitivity. Yet while increasing the TAG synthesis capacity by, for example, training has been shown to improve insulin sensitivity, there is no evidence for a causative role of impaired TAG synthesis capacity in the development of obesity-associated insulin resistance.

\subsection{TAG breakdown}

Lipid turnover is not only determined by TAG synthesis but also by TAG lipolysis. In skeletal muscle, two major lipases have been identified that are responsible for complete TAG lipolysis: ATGL and HSL. Adipose triglyceride lipase (ATGL) hydrolyses TAG to form
DAG [113], whereas HSL mainly acts on DAG [114,115]. When increased ATGL activity is not counterbalanced by increased hormone-sensitive lipase (HSL) or DGAT activity, intermediates will accumulate. In vivo microdialysis studies have demonstrated impaired lipolysis in skeletal muscle of obese subjects [116], suggesting that disturbances in the regulation of lipolysis may contribute to the development of obesity-associated comorbidities. In addition, several observational studies have shown alterations in the expression of proteins involved in lipolysis in skeletal muscle of obese and type 2 diabetic subjects. Jocken et al. measured lipase expression levels in insulin-resistant obese subjects compared with lean controls and showed that HSL was decreased while ATGL was increased without changes in CGI-58, a cofactor for ATGL activity. These changes concurrent with a lower DAG hydrolase activity may be a manifestation of incomplete lipolysis [42]. Surprisingly, the DAG level was decreased in the insulin-resistant obese subjects compared with the lean controls, indicating that the decreased DAG hydrolase and normal TAG hydrolase activity in obese subjects did not result in increased DAG. This absence of an effect on DAG accumulation raises the question whether the ratio of DAG to TAG hydrolase activity is of physiological importance for lipid-induced insulin resistance. Moreover, compensation by TAG-synthesis related proteins like DGAT might balance out intracellular DAG and TAG levels, thus protecting from accumulation of lipotoxic DAG species. Moro et al. determined DAG and TAG levels as well as lipase activities in skeletal muscle biopsies from lean, obese and type 2 diabetic subjects. In contrast to the study of Jocken et al. [42], DAG levels were increased. Additionally, a direct association with the ratio of DAG hydrolase to TAG hydrolase activity (an index of incomplete triacylglycerol hydrolysis) was observed, which explained 54\% of the variance in DAG [7]. TAG hydrolase activity was increased only in female obese and type 2 diabetic subjects compared to lean controls [7]. Although Jocken et al. [42] only used male subjects, gender differences most likely do not explain the differences in DAG levels between the two studies, as no differences in DAG levels between males and females have been observed before [7]. Coen et al. showed decreased ATGL and HSL gene expression in obese insulin resistant compared with BMI-matched insulin sensitive controls, while DAG levels were similar [45]. In contrast to these studies, Li et al. showed that ATGL and HSL protein levels were not altered in skeletal muscle of obese women compared with lean women and that there were no differences in phosphorylation of specific sites known to affect HSL activity [101].

Recently, Badin et al. showed an imbalance between ATGL and HSL protein expression and activity in obese diabetics versus lean controls [117], consistent with the studies of Moro et al. [7] and Jocken et al. [42]. Furthermore, it was shown that an imbalance of ATGL relative to HSL promotes DAG accumulation and leads to insulin resistance at least in part through the DAG-induced PKC activity [117]. However, in this study only obese type 2 diabetics and not NGT obese subjects displayed alterations in lipase protein content, in contrast with the data of Jocken et al. [42]. It was suggested that these differences in study outcomes could be explained by age differences, since Badin et al. included younger obese subjects [117]. This age-effect deserves further attention.

Thus, studies in which lipase levels and activity were measured in obese and/or type 2 diabetic persons do not show consistent results. If the suggested importance of the ratio of TAG to DAG hydrolysis would be true, one could reason that TAG hydrolase activity is not as strictly regulated as DAG hydrolase activity, which may lead to a mismatch and incomplete lipolysis in obese subjects with excess IMCL. However, intramyocellular TAG and DAG hydrolysis capacity was measured in homogenates derived from frozen samples [7,42] and therefore represents maximal capacity as 
opposed to physiological lipase activity. Cell studies showed that ATGL and HSL activity is tightly regulated by coactivation and repression by regulatory proteins. ATGL activity is dependent on CGI-58 (activator), G0S2 (suppressor) and perilipins for docking on the LD and the regulation of lipolysis upon protein kinase $A$ (PKA) stimulation [118-121]. Thus, endogenous intracellular lipase activity is not only dependent on ATGL and HSL expression and enzyme activity, but is highly dependent on subcellular localization and the presence and activation of other proteins. Therefore, lipase protein expression and enzyme activity alone presumably do not give enough information to draw conclusion about the importance of disturbances in skeletal muscle lipolysis in lipid-induced insulin resistance. Moreover, it is currently unknown whether ATGLmediated lipolysis gives rise to 1,2-DAG, which is considered the lipotoxic DAG intermediate capable of activity PKC [36]. The stereospecificity of the ATGL reaction needs to be elucidated. Taken together, it is still unclear whether the ratio of ATGL and HSL activity is involved in the development of lipid-induced insulin resistance.

\subsection{Lipid turnover and balances with oxidative capacity}

The aim of intramyocellular lipid dynamics in normal physiology is to provide intracellular fatty acids for oxidation when needed. In endurance-trained athletes, elevated IMCL storage serves as an important fuel store for prolonged exercise bouts and coincides with a high capacity to oxidize these fatty acids [122,123]. Interestingly, type 2 diabetic patients have impaired mitochondrial function compared to obese NGT while having similar IMCL levels [19]. Therefore, a proper balance between IMCL storage and the myocellular oxidative capacity appears important to prevent detrimental effects of IMCL accumulation. Indeed, studies using stable isotope tracer technology to study usage of IMCL during exercise revealed that IMCL was an important substrate during exercise [122,123]. Moreover, the increased IMCL storage in endurance-trained athletes $[18,20]$ indicates an increased IMCL resynthesis capacity. It could be reasoned that lipid droplets in skeletal muscle of sedentary subjects have a low turnover rather than being frequently degraded and resynthesized, which might affect the subcellular distribution, organelle interactions and lipotoxic events. It is unclear to date whether IMCL usage and turnover is indeed impaired in obese and type 2 diabetic subjects. While Standl et al. [124] did not find any differences in IMCL use during exercise between type 2 diabetics and healthy lean controls, IMCL usage was demonstrated to be low in obese and type 2 diabetic subjects during exercise $[122,125]$. The beneficial effects of exercise training for type 2 diabetics, improved insulin sensitivity paralleled with increased IMCL storage [21,22], indicate that a balance in FA uptake, IMCL storage and resynthesis, and oxidative metabolism improves insulin sensitivity. Interestingly, FFA-induced insulin resistance via lipid infusion was completely reversed by a single exercise session [102], further supporting the importance of exercise-induced IMCL resynthesis in the prevention of lipid-induced insulin resistance. Increased lipid turnover on the long term, for example as a

result of exercise training, is usually paralleled by fiber type switches towards the more oxidative slow-twitch type I fibers $[45,77,126,127]$, increased oxidative capacity and increased intramyocellular TAG synthesis. Thus, elevated lipid turnover and IMCL resynthesis are components of the physiological adaptation to training and increased metabolic capacity. Proper balance between IMCL synthesis, lipolysis and oxidative metabolism is important for the protection against lipotoxicity. The importance of the rate of lipid turnover per se on subcellular distribution and buildup of lipotoxic intermediates requires further research.

\subsection{IMCL dynamics; concluding remarks}

Skeletal muscle lipid turnover is disturbed in obese and type 2 diabetic subjects. However, the mechanisms involved deserve further investigation. The regulation of lipid synthesis and lipolysis in skeletal muscle and its role in lipid-induced insulin resistance is complex and dependent on the interplay of different proteins. Disturbing this balance might lead to accumulation of lipid intermediates that have the potential to impair insulin signaling. Measurements of enzyme levels in skeletal muscle biopsies, however, represent static snap shots of the situation, while lipid metabolism is a highly dynamic process. Therefore, further research is warranted. Tracer studies and primary myotube cultures could provide valuable information on skeletal muscle lipid dynamics.

\section{Lipid droplets \& lipid droplet coating proteins}

As outlined above, lipid accumulation in the form of lipid droplets (LDs) in muscle is a dynamic process that is heavily regulated by TAG synthetases and lipases. Since the recognition of LDs as dynamic organelles as opposed to being merely silent components of a cell, lipid droplet coat proteins have gained attention. LDs are composed of a neutral lipid core surrounded by a phospholipid monolayer and a protein coat. Cells contain a heterogeneous population of LDs with differences in lipid composition and protein coating. The protein coat of LDs contains a variety of different proteins involved in LD dynamics, including proteins involved in TAG metabolism, LD synthesis and breakdown, fusion and fission of LDs, intracellular trafficking and interorganelle interactions [128-131]. Research in this field is still in its infancy, but mounting evidence suggests a role for LD-coat proteins in protecting against lipotoxicity and insulin resistance. The lipid core contains DAG, TAG, cholesterolesters and free FAs [132]. One could hypothesize that storage of lipids in the LD is not harmful as opposed to accumulation of lipids elsewhere in the cell. High expression levels of LD-coat proteins might therefore provide a depot for intracellular lipids, thus sequestering (toxic) lipid species in LDs. Moreover, the lipid droplet coat is an important interface for lipid metabolism determining rates of lipid synthesis and lipolysis.

\subsection{Lipid droplet coat proteins: perilipins}

The best-characterized group of LD coat proteins is the perilipin (PLIN) protein family. PLIN1 (perilipin) is specific for adipose tissue, PLIN2 (ADRP, adipophilin) [133-135], PLIN3 (TIP47) [135], PLIN4 (S3-12) [136] and PLIN5 (OXPAT, MLDP, LSDP5) [133,137-139] are expressed in muscle. Perilipins have been demonstrated to interact with key players in lipid metabolism [119-121], indicating that the protein coat of the LD is the interface for intracellular lipid metabolism. Little is known about the specific roles of the perilipins in skeletal muscle, but it could be suggested that the abundance of perilipin proteins might facilitate the creation of a depot for intracellular lipids and might modulate TAG synthesis and breakdown. Studies performed in vitro and in vivo in tissues other than muscle have demonstrated that perilipins increase intracellular lipid levels by inhibiting lipolysis and facilitating LD synthesis, while protecting against lipotoxic events $[138,140,141]$, providing additional support for the hypothesis that neutral lipid storage per se does not induce lipotoxicity. Moreover, sequestering lipid intermediates towards storage in LDs rather than accumulation in/near the membranes or at other intracellular locations could prevent lipotoxicity without altering total intermediate storage. However, little is known about the exact composition of lipid droplets and this, therefore, deserves further attention. 
Interestingly, in a human study in which no differences were found regarding the protein expression of TAG synthesis or lipolysis-related proteins, protein abundance of PLIN3 was lower in muscle of obese versus lean controls when expressed relative to intramyocellular TAG content [101]. Moreover, PLIN2 gene expression levels were lower in insulin resistant obese subjects versus BMI-matched insulin sensitive controls, with PLIN2 levels correlating positively with the rate of glucose disposal [45]. Additionally, although no differences were found in PLIN2 protein expression in diabetic versus obese control subjects, both weight loss and insulin-sensitizing drugs (troglitazone or metformin) resulted in increased protein expression of PLIN2 [134]. In a study performed in our group, we found no differences in skeletal muscle PLIN2 protein content when comparing type 2 diabetes patients with BMImatched controls, two groups with similar IMCL levels. The same was true for PLIN5. However, an 8 week treatment with the PPAR $\gamma$ agonist rosiglitazone decreased PLIN2 and PLIN5 expression without changes in IMCL [133], which might be explained by a starting shift towards less ectopic fat accumulation and does not rule out a potential beneficial effect of perilipins. A $16 \mathrm{~h}$ lipid infusion after a 90 min exercise session did not affect expression of perilipins 2-5 in skeletal muscle of lean women, while IMCL was increased with $30 \%$ [105], indicating that short-term elevation of IMCL storage is not necessarily accompanied by increased perilipin protein expression. Information on the adaptations of PLIN activities upon long term increased fatty acid availability in humans is lacking.

We and others $[142,143]$ have recently shown that next to its presence in the lipid droplet coat, PLIN5 is present at the interface of LDs with mitochondria, as well as in the mitochondria. Furthermore, PLIN5 induces interactions of lipid droplets with mitochondria. Besides, PLIN5 regulates lipolysis by inhibiting ATGL activity under basal conditions and stimulating lipolysis upon PKA stimulation [119-121]. Therefore, PLIN5 potentially is a very important regulator of oxidative metabolism in muscle matching intracellular lipid load with downstream mitochondrial metabolism. Its exact role in mitochondria and lipid droplet dynamics requires further study.

Reports describing phenotypes of animal models of overexpression, knockdown or inhibition of perilipins are limited. PLIN2 knockout or inhibition showed contradictory results with respect to whole body or liver insulin sensitivity [140,144-146]. That is, lowering of PLIN2 activity was demonstrated to improve liver insulin sensitivity in mice models of PLIN2 inhibition [145,146], while siRNA-mediated knockdown of PLIN2 plus PLIN3 in liver cells impaired insulin sensitivity [140]. It should be noted that in the latter study, PLIN2 knockdown coincided with compensatory increased PLIN3 expression at the LD surface. Therefore, effects of knockdown of both PLIN3 and PLIN2 on insulin signaling was investigated [140]. In the first two studies [145,146], potential compensation by other PLIN members at the LD surface in combination with lower intracellular lipid storage might have resulted in the beneficial effects of PLIN2 knockdown. PLIN2 knockouts crossed with ob/ob mice showed improved insulin sensitivity in both liver and muscle compared with ob/ob-PLIN2 ${ }^{+/+}$mice [144]. We recently overexpressed PLIN2 in tibialis anterior of rats by means of gene-electrotransfer. This intervention appeared to improve skeletal muscle insulin sensitivity despite increased intramyocellular lipid storage (unpublished data).

Thus, based on present knowledge we cannot conclude whether perilipins might have the potential to protect against lipid-induced insulin resistance. Moreover, expression levels of perilipins might reflect adaptations in the cellular adaptation towards increased or decreased lipid load, thus following the pattern of myocellular fat storage. Nevertheless, based on the information from transgenic animal models and cell studies, genetic variation in LD-coat proteins (single nucleotide polymorphisms), as was described for
PLIN1 in human DNA [147-149] and PLIN2 in pig DNA [150], might be one of the factors determining genetic predisposition for development of obesity and type 2 diabetes. However, further human genetic characterization studies and gain- and loss of function animal and cell models are warranted to further characterize the role of PLIN polymorphisms in (ectopic) fat storage and lipid-induced insulin resistance.

\subsection{Lipid droplet dynamics; future perspectives}

\subsubsection{Lipid droplet coat proteins other than the perilipins}

Other LD-coat proteins shown to be present in muscle include members of the CIDE (cell death-inducing DFF45-like effector) family, in particular Cidec/FSP27 [151-153], FIT1 and -2 [154,155], and SNARE proteins [156-159], but not a lot is known about their function. Interestingly, while total SNAP-23 protein levels were increased in T2DM patients [160,161], the amount of SNAP-23 in skeletal muscle plasma membranes was lower in type 2 diabetes patients compared to controls and the amount of membrane SNAP-23 correlated with systemic insulin sensitivity [160,161]. Exocytosis of GLUT4 vesicles with the plasma membrane of insulin sensitive tissues as well as LD fusion are SNARE-mediated processes and high-jacking of SNAP-23 by LDs has been suggested to limit SNAP-23 availability for GLUT4 translocation $[160,162,163]$ but is beyond the scope of this review. Moreover, this list of muscular LD coat proteins is expected to expand because this field is still in its infancy.

\subsubsection{Lipid droplet size}

LD size might be a parameter influencing IMCL-storage induced lipotoxicity. An increased surface to volume ratio, i.e. smaller lipid droplets, would result in a greater LD coating area, potentially resulting in an increased capacity to mobilize lipids, which might be beneficial. However, this would also result in an increased binding surface area for lipases, perhaps resulting in increased lipid intermediates. Not a lot is known about the importance of lipid droplet size regarding lipotoxic potential. A weight loss and exercise program resulted in decreased LD size as determined by confocal microscopy paralleled by changes in insulin sensitivity [164]. Furthermore, rosiglitazone improved insulin sensitivity in parallel with smaller LDs [165], and large LDs were demonstrated to be associated with the development of diabetes in a study in which LD size was determined with electron microscopy (EM) [166]. On the other hand, no differences in LD size were observed after a seven week endurance training period in lean untrained men and women using EM [167]. Furthermore, in the study of Van Loon et al. [18] no differences in LD size were found when comparing trained, obese sedentary and obese diabetics nor in another study comparing obese subjects with lean controls [168]. A limitation of these two studies is the use of standard immunofluorescent microscopy, which is - in contrast to confocal microscopy suboptimal to determine true LD size as the 2-dimensional section plane does not necessarily reflect the middle, largest diameter of all LDs. Basically, the same limitation holds true for EM determinations of LD size. Further research is needed to identify whether LD size is an important parameter in lipid-induced insulin resistance.

\subsubsection{Intracellular localization and organelle interactions}

Intramyocellular LDs are mainly localized in between the myofibers, in close contact with mitochondria (Fig. 2) and are less prominently present in the subsarcolemmal region. Malenfant et al. described a more central localization of LDs (i.e. less LDs in the subsarcolemmal region compared with the peripheral areas) in myofibers of NGT obese subjects compared to lean individuals [168]. Yet, in a study of Nielsen et al., it was concluded that subsarcolem- 


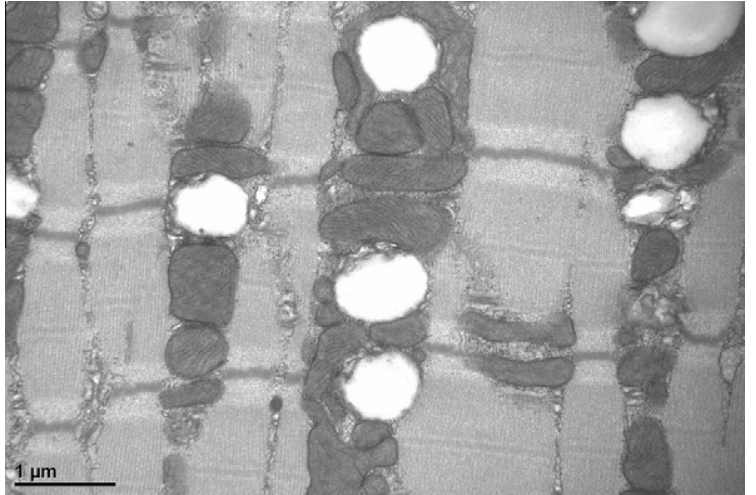

Fig. 2. Transmission electron microscopy image of rat tibialis anterior muscle showing intermyofibrillar lipid droplets and adjacent mitochondria.

mal LDs storage was increased in type 2 diabetics when compared to BMI-matched controls, using the more accurate method of ultrastructural determinations with electron microscopy [169]. Thus, LDs storage might shift from the interior towards the subsarcolemma during the transition from obesity towards overt type 2 diabetes. However, data is limited to firmly conclude on the importance of subcellular LD localization in the development of insulin resistance.

The effects of subcellular localization of LDs on insulin sensitivity might be mediated by interactions of LDs with other subcellular compartments like mitochondria, the plasma membrane, and the sarcoplasmic reticulum (SR, the muscle-specific type of smooth ER). An oversupply of lipids to organelles might impair organelle function. On the other hand, it could be reasoned that a close apposition to SR or mitochondria might be beneficial for lipid handling. Complexes of SR, mitochondria and LDs might be the intracellular interface for lipid metabolism. The tubular invaginations of the sarcolemma ensure that the SR is in direct contact with the extracellular space of the muscle. These tubular invaginations are found on both sides of the z-line. Intermyofibrillar lipid droplets and mitochondria are usually found near these z-lines. The close apposition of LDs and mitochondria was already demonstrated in the early seventies by Hoppeler and colleagues [170]. They suggested that the contact surface area of LDs was the transfer site for fatty acids towards oxidative metabolism and that a larger contact surface area would be beneficial for the efficiency of lipid oxidative metabolism [171,172]. Tarnapolsky et al. showed that a 7-week endurance-training period in lean untrained men and women significantly increased the number of LDs in contact with mitochondria [167]. One could hypothesize that lipid droplets that are interacting with mitochondria are metabolically active LDs with a well-regulated rate and timing of lipolysis matched with downstream metabolism. That is, a close interaction between LDs and mitochondria ensures efficient utilization of lipolysis-derived FAs in situations of increased energy demand, thereby preventing high intracellular FA levels. Thus, interactions of LDs with SR and mitochondria might ensure controlled lipid metabolism and loss of interactions or a higher ratio of LDs to mitochondria might potentially be one of the intermediate steps in the development of lipotoxicity-induced insulin resistance. Moreover, proteins present on the mitochondrial outermembrane and/or in the LD coat are presumably needed for interorganelle interactions. However, so far no evidence is available for a role of LD-mitochondria interactions in determining insulin sensitivity of skeletal muscle and clearly further research in this area is warranted to unravel the dynamics of interorganelle interactions.

\section{Conclusions and perspectives}

The importance of intramyocellular lipid accumulation in the development of type 2 diabetes is firmly established and can be attributed to a disbalance in skeletal muscle lipid influx, lipid metabolism, and oxidative capacity. The mechanisms involved in lipid-induced insulin resistance, however, are still not fully unraveled. In animal and cell studies, lipid intermediates like DAG, ceramides, LC-FA-CoA and acylcarnitines all have the potential to induce insulin resistance. However, human studies show conflicting results, and are if anything not pointing towards one mechanism that can be held responsible for the muscular insulin resistance in type 2 diabetes. Rather, the strong interindividual variation and the inconsistencies in the broad array of studies performed so far indicate that there are several routes towards lipidinduced insulin resistance. Furthermore, it should not be ignored that the available data are merely correlative, describe snap shots and focus on one or a few parameters, while lipid metabolism is a highly complex and dynamic process. Based on available evidence, we conclude that total levels of DAG, ceramides and LC-FA-CoA are not appropriate predictors of obesity-associated insulin resistance.

Nevertheless, given the fact that these lipid species have the potential of impairing insulin signaling, it appears that the consequences of its accumulation in human skeletal muscle are multifactorial and dependent on specific characteristics, the latter might include the degree of saturation, chain length, stereo specificity and intracellular localization. Recently, research in this field has shifted towards the packaging of lipids into lipid droplets and the related lipid droplet dynamics. The heterogeneity and dynamic nature of lipid droplets indicate that lipid droplet characteristics and expression of lipid droplet-coat proteins are determinants of intramyocellular lipotoxicity. Information on this issue is still limited albeit promising, and definitely deserves further attention for our understanding of obesity-related diabetes and might provide targets for prevention.

\section{Acknowledgements}

M. Bosma was financially supported by NUTRIM and the graduate school VLAG. A VICI (grant 918.96.618) and a VIDI (grant 917.66.359) for innovative research from the Netherlands Organization for Scientific Research (NWO) supports the work of P. Schrauwen and M. Hesselink, respectively.

\section{References}

[1] WHO. Obesity and overweight - Fact sheet N 311. 2011.

[2] Lee DE, Kehlenbrink S, Lee H, Hawkins M, Yudkin JS. Getting the message across: mechanisms of physiological cross talk by adipose tissue. Am J Physiol Endocrinol Metab 2009;296:E1210-29.

[3] McGarry JD. What if Minkowski had been ageusic? An alternative angle on diabetes. Science 1992;258:766-70.

[4] Forouhi NG, Jenkinson G, Thomas EL, Mullick S, Mierisova S, Bhonsle U, et al. Relation of triglyceride stores in skeletal muscle cells to central obesity and insulin sensitivity in European and South Asian men. Diabetologia 1999;42:932-5.

[5] Machann J, Bachmann OP, Brechtel K, Dahl DB, Wietek B, Klumpp B, et al. Lipid content in the musculature of the lower leg assessed by fat selective MRI: Intra- and interindividual differences and correlation with anthropometric and metabolic data. J Magn Reson Imaging 2003;17:350-7.

[6] Misra A, Sinha S, Kumar M, Jagannathan NR, Pandey RM. Proton magnetic resonance spectroscopy study of soleus muscle in non-obese healthy and type 2 diabetic Asian Northern Indian males: high intramyocellular lipid content correlates with excess body fat and abdominal obesity. Diabet Med 2003;20:361-7.

[7] Moro C, Galgani JE, Luu L, Pasarica M, Mairal A, Bajpeyi S, et al. Influence of gender, obesity, and muscle lipase activity on intramyocellular lipids in sedentary individuals. J Clin Endocrinol Metab 2009;94:3440-7. 
[8] Sinha R, Dufour S, Petersen KF, LeBon V, Enoksson S, Ma Y-Z, et al. Assessment of skeletal muscle triglyceride content by $1 \mathrm{H}$ nuclear magnetic resonance spectroscopy in lean and obese adolescents. Diabetes 2002;51:1022-7.

[9] Aguer C, Mercier J, Yong Wai Man C, Metz L, Bordenave S, Lambert K, et al. Intramyocellular lipid accumulation is associated with permanent relocation ex vivo and in vitro of fatty acid translocase (FAT)/CD36 in obese patients. Diabetologia 2010;53:1151-63.

[10] Goodpaster BH, Theriault R, Watkins SC, Kelley DE. Intramuscular lipid content is increased in obesity and decreased by weight loss. Metabolism 2000;49:467-72.

[11] Pan DA, Lillioja S, Kriketos AD, Milner MR, Baur LA, Bogardus C, et al. Skeletal muscle triglyceride levels are inversely related to insulin action. Diabetes 1997;46:983-8

[12] Gray RE, Tanner CJ, Pories WJ, MacDonald KG, Houmard JA. Effect of weight loss on muscle lipid content in morbidly obese subjects. Am J Physiol Endocrinol Metab 2003;284:E726-32.

[13] Jazet I, Schaart G, Gastaldelli A, Ferrannini E, Hesselink M, Schrauwen P, et al. Loss of $50 \%$ of excess weight using a very low energy diet improves insulinstimulated glucose disposal and skeletal muscle insulin signalling in obese insulin-treated type 2 diabetic patients. Diabetologia 2008;51:309-19.

[14] Solomon TPJ, Sistrun SN, Krishnan RK, Del Aguila LF, Marchetti CM, O'Carroll $\mathrm{SM}$, et al. Exercise and diet enhance fat oxidation and reduce insulin resistance in older obese adults. J Appl Physiol 2008;104:1313-9.

[15] Tamura Y, Tanaka Y, Sato F, Choi JB, Watada H, Niwa M, et al. Effects of diet and exercise on muscle and liver intracellular lipid contents and insulin sensitivity in type 2 diabetic patients. J Clin Endocrinol Metab 2005;90:3191-6.

[16] Toledo FGS, Menshikova EV, Azuma K, Radiková Z, Kelley CA, Ritov VB, et al. Mitochondrial capacity in skeletal muscle is not stimulated by weight loss despite increases in insulin action and decreases in intramyocellular lipid content. Diabetes 2008;57:987-94.

[17] Bachmann OP, Dahl DB, Brechtel K, Machann Jr, Haap M, Maier T, et al. Effects of intravenous and dietary lipid challenge on intramyocellular lipid content and the relation with insulin sensitivity in humans. Diabetes 2001;50:2579-84

18] Van Loon LJC, Koopman R, Manders R, van der Weegen W, van Kranenburg GP, Keizer HA. Intramyocellular lipid content in type 2 diabetes patients compared with overweight sedentary men and highly trained endurance athletes. Am J Physiol Endocrinol Metab 2004;287:E558-65.

[19] Schrauwen-Hinderling V, Kooi M, Hesselink M, Jeneson J, Backes W, van Echteld C, et al. Impaired in vivo mitochondrial function but similar intramyocellular lipid content in patients with type 2 diabetes mellitus and BMI-matched control subjects. Diabetologia 2007;50:113-20.

[20] Goodpaster BH, He J, Watkins S, Kelley DE. Skeletal muscle lipid content and insulin resistance. evidence for a paradox in endurance-trained athletes. J Clin Endocrinol Metab 2001;86:5755-61.

[21] Dubé JJ, Amati F, Stefanovic-Racic M, Toledo FGS, Sauers SE, Goodpaster BH. Exercise-induced alterations in intramyocellular lipids and insulin resistance. the athlete's paradox revisited. Am J Physiol Endocrinol Metab 2008;294:E882-8.

[22] Meex RCR, Schrauwen-Hinderling VB, Moonen-Kornips E, Schaart G, Mensink M, Phielix E, et al. Restoration of muscle mitochondrial function and metabolic flexibility in type 2 diabetes by exercise training Is paralleled by increased myocellular fat storage and improved insulin sensitivity. Diabetes 2010;59:572-9.

[23] Bergman BC, Perreault L, Hunerdosse DM, Koehler MC, Samek AM, Eckel RH. Increased intramuscular lipid synthesis and low saturation relate to insulin sensitivity in endurance-trained athletes. J Appl Physiol 2010;108: 1134-41.

[24] Schaffer JE. Lipotoxicity: when tissues overeat. Curr Opin Lipidol $2003 ; 14: 281-7$

[25] Liu L, Shi X, Choi CS, Shulman GI, Klaus K, Nair KS, et al. Paradoxical coupling of triglyceride synthesis and fatty acid oxidation in skeletal muscle overexpressing DGAT1. Diabetes 2009;58:2516-24.

[26] Timmers S, den Bosch J, Hesselink MKC, van Beurden D, Schaart G, Ferraz MJ et al. PLoS ONE 2011;6:e14503.

[27] Chibalin AV, Leng Y, Vieira E, Krook A, Björnholm M, Long YC, et al. Downregulation of diacylglycerol kinase delta contributes to hyperglycemiainduced insulin resistance. Cell 2008;132:375-86.

[28] van Blitterswijk WJ, Houssa B. Properties and functions of diacylglycerol kinases. Cell Signal 2000;12:595-605.

[29] Chavez JA, Summers SA. Characterizing the effects of saturated fatty acids on insulin signaling and ceramide and diacylglycerol accumulation in 3T3-L1 adipocytes and C2C12 myotubes. Arch Biochem Biophys 2003;419:101-9.

[30] Montell E, Turini M, Marotta M, Roberts M, Noe V, Ciudad CI, et al. DAG accumulation from saturated fatty acids desensitizes insulin stimulation of glucose uptake in muscle cells. Am J Physiol Endocrinol Metab 2001;280:E229-37.

[31] Idris I, Gray S, Donnelly R. Protein kinase C activation: Isozyme-specific effects on metabolism and cardiovascular complications in diabetes. Diabetologia 2001;44:659-73.

[32] Samuel VT, Petersen KF, Shulman GI. Lipid-induced insulin resistance: unravelling the mechanism. The Lancet 2010;375:2267-77.

[33] Turban S, Hajduch E. Protein kinase C isoforms: mediators of reactive lipid metabolites in the development of insulin resistance. FEBS Lett 2011;585:269-74
[34] Boni LT, Rando RR. The nature of protein kinase C activation by physically defined phospholipid vesicles and diacylglycerols. J Biol Chem 1985;260:10819-25

[35] Goñi FM, Alonso A. Structure and functional properties of diacylglycerols in membranes. Prog Lipid Res 1999;38:1-48.

[36] Wakelam MJO. Diacylglycerol - when is it an intracellular messenger? Biochim Biophys Acta 1998;1436:117-26.

[37] Saha AK, Kurowski TG, Colca JR, Ruderman NB. Lipid abnormalities in tissues of the KKAy mouse: effects of pioglitazone on malonyl-CoA and diacylglycerol. Am J Physiol Endocrinol Metab 1994;267:E95-E101.

[38] Turinsky J, O'Sullivan DM, Bayly BP. 1, 2-Diacylglycerol and ceramide levels in insulin-resistant tissues of the rat in vivo. J Biol Chem 1990;265:16880-5.

[39] Itani SI, Ruderman NB, Schmieder F, Boden G. Lipid-induced insulin resistance in human muscle is associated with changes in diacylglycerol, protein kinase C, and IkBa. Diabetes 2002;51:2005-11.

[40] Moro C, Bajpeyi S, Smith SR. Determinants of intramyocellular triglyceride turnover: implications for insulin sensitivity. Am J Physiol Endocrinol Metab 2008;294:E203-13.

[41] Straczkowski M, Kowalska I, Baranowski M, Nikolajuk A, Otziomek E, Zabielski $\mathrm{P}$, et al. Increased skeletal muscle ceramide level in men at risk of developing type 2 diabetes. Diabetologia 2007;50:2366-73.

[42] Jocken JWE, Moro C, Goossens GH, Hansen D, Mairal A, Hesselink MKC, et al. Skeletal muscle lipase content and activity in obesity and type 2 diabetes. J Clin Endocrinol Metab 2010:jc.2010-0776.

[43] Thrush AB, Brindley DN, Chabowski A, Heigenhauser GJ, Dyck DJ. Skeletal muscle lipogenic protein expression is not different between lean and obese individuals: a potential factor in ceramide accumulation. J Clin Endocrinol Metab 2009;94:5053-61.

[44] Anastasiou CA, Kavouras SA, Lentzas Y, Gova A, Sidossis LS, Melidonis A. Diabetes mellitus is associated with increased intramyocellular triglyceride, but not diglyceride, content in obese humans. Metabolism 2009;58: $1636-42$.

[45] Coen PM, Dubé JJ, Amati F, Stefanovic-Racic M, Ferrell RE, Toledo FGS, et al. Insulin resistance is associated with higher intramyocellular triglycerides in type I but not type II myocytes concomitant with higher ceramide content Diabetes 2009;59:80-8.

[46] Perreault L, Bergman BC, Hunerdosse DM, Playdon MC, Eckel RH. Inflexibility in intramuscular triglyceride fractional synthesis distinguishes prediabetes from obesity in humans. Obesity 2010;18:1524-31.

[47] Perreault L, Bergman BC, Hunerdosse DM, Eckel RH. Altered intramuscula lipid metabolism relates to diminished insulin action in men, but not women, in progression to diabetes. Obesity 2010;18:2093-100.

[48] Bruce CR, Thrush AB, Mertz VA, Bezaire V, Chabowski A, Heigenhauser GJF, et al. Endurance training in obese humans improves glucose tolerance and mitochondrial fatty acid oxidation and alters muscle lipid content. Am J Physiol Endocrinol Metab 2006;291:E99-E107.

[49] Dubé J, Amati F, Toledo F, Stefanovic-Racic M, Rossi A, Coen P, et al. Effects of weight loss and exercise on insulin resistance, and intramyocellular triacylglycerol, diacylglycerol and ceramide. Diabetologia 2011:1-10.

[50] Bajaj M, Baig R, Suraamornkul S, Hardies LJ, Coletta DK, Cline GW, et al. Effects of pioglitazone on intramyocellular fat metabolism in patients with type 2 diabetes mellitus. J Clin Endocrinol Metab 2010;95:1916-23.

[51] Anastasiou CA, Kavouras SA, Lentzas Y, Gova A, Sidossis LS, Melidonis A Moderate weight loss depletes intramyocellular triglycerides but has no effect on diglycerides in type II diabetes. Eur J Clin Nutr 2010;64:328-30.

[52] Van Hees AMJ, Jans A, Hul GB, Roche HM, Saris WHM, Blaak EE. Skeletal muscle fatty acid handling in insulin resistant men. Obesity 2011;19:1350-9.

[53] Kuerschner L, Moessinger C, Thiele C. Imaging of lipid biosynthesis: how neutral lipid enters lipid droplets. Traffic 2008;9:338-52.

[54] Bruce CR, Hoy AJ, Turner N, Watt MJ, Allen TL, Carpenter K, et al. Overexpression of carnitine palmitoyltransferase- 1 in skeletal muscle is sufficient to enhance fatty acid oxidation and improve high fat diet-induced insulin resistance. Diabetes 2009;58:550-8.

[55] Choi CS, Befroy DE, Codella R, Kim S, Reznick RM, Hwang Y-J, et al. Paradoxica effects of increased expression of PGC-1alpha on muscle mitochondrial function and insulin-stimulated muscle glucose metabolism. Proc Natl Acad Sci 2008;105:19926-31.

[56] Choi CS, Fillmore JJ, Kim JK, Liu ZX, Kim S, Collier EF, et al. Overexpression of uncoupling protein 3 in skeletal muscle protects against fat-induced insulin resistance. J Clin Invest 2007;117:1995-2003.

[57] Summers SA. Ceramides in insulin resistance and lipotoxicity. Prog Lipid Res 2006;45:42-72.

[58] Blachnio-Zabielska A, Baranowski M, Zabielski P, Gorski J. Effect of high fat diet enriched with unsaturated and diet rich in saturated fatty acids on sphingolipid metabolism in rat skeletal muscle. J Cell Physio 2010;225:786-91.

[59] Holland WL, Brozinick JT, Wang L-P, Hawkins ED, Sargent KM, Liu Y, et al. Inhibition of ceramide synthesis ameliorates glucocorticoid-, saturated-fat-, and obesity-induced insulin resistance. Cell Metab 2007:5:167-79.

[60] Merrill AH. De novo sphingolipid biosynthesis: a necessary, but dangerous, pathway. J Biol Chem 2002;277:25843-6.

[61] Summers SA. Sphingolipids and insulin resistance. the five Ws. Curr Opin Lipidol 2010;21:128-35.

[62] Chavez JA, Knotts TA, Wang L-P, Li G, Dobrowsky RT, Florant GL, et al. A role for ceramide, but not diacylglycerol, in the antagonism of insulin signa transduction by saturated fatty acids. J Biol Chem 2003;278:10297-303. 
[63] Kabayama K, Sato T, Saito K, Loberto N, Prinetti A, Sonnino S, et al Dissociation of the insulin receptor and caveolin-1 complex by ganglioside GM3 in the state of insulin resistance. Proc Natl Acad Sci 2007;104:13678-83.

[64] Novgorodov SA, Wu BX, Gudz TI, Bielwaski J, Ovchinnikova TV, Hannun YA, et al. Novel pathway of ceramide production in mitochondria: Thioesterase and neutral ceramidase produce ceramide from sphingosine and acyl-COA. J Biol Chem 2011;286:25352-62.

[65] Adams JM, Pratipanawatr T, Berria R, Wang E, DeFronzo RA, Sullards MC, et al. Ceramide content is increased in skeletal muscle from obese insulin-resistant humans. Diabetes 2004;53:25-31.

[66] Serlie MJ, Meijer AJ, Groener JE, Duran M, Endert E, Fliers E, et al. Short-term manipulation of plasma free fatty acids does not change skeletal muscle concentrations of ceramide and glucosylceramide in lean and overweight subjects. J Clin Endocrinol Metab 2007;92:1524-9.

[67] Skovbro M, Baranowski M, Skov-Jensen C, Flint A, Dela F, Gorski J, et al. Human skeletal muscle ceramide content is not a major factor in muscle insulin sensitivity. Diabetologia 2008;51:1253-60.

[68] Nordby P, Prats C, Kristensen D, Ekroos K, Forsberg G, Andersen J, et al. Muscle ceramide content in man is higher in type I than type II fibers and not influenced by glycogen content. Eur J of Appl Physiol 2010;109: 935-43.

[69] Hoeg LD, Sjoberg KA, Jeppesen J, Jensen TE, Frosig C, Birk JB, et al. Lipidinduced insulin resistance affects women less than men and is not accompanied by inflammation or impaired proximal insulin signaling. Diabetes 2011;60:64-73.

[70] Straczkowski M, Kowalska I, Nikolajuk A, Dzienis-Straczkowska S, Kinalska I, Baranowski $M$, et al. Relationship between insulin sensitivity and sphingomyelin signaling pathway in human skeletal muscle. Diabetes 2004;53:1215-21.

[71] Vistisen B, Hellgren LI, Vadset T, Scheede-Bergdahl C, Helge Jr W, Dela F, et al. Effect of gender on lipid-induced insulin resistance in obese subjects. Eur J Endocrinol 2008;158:61-8.

[72] Ellis BA, Poynten A, Lowy AJ, Furler SM, Chisholm DJ, Kraegen EW, et al. Longchain acyl-CoA esters as indicators of lipid metabolism and insulin sensitivity in rat and human muscle. Am J Physiol Endocrinol Metab 2000;279: E554-60.

[73] Hulver MW, Berggren JR, Cortright RN, Dudek RW, Thompson RP, Pories WJ, et al. Skeletal muscle lipid metabolism with obesity. Am J Physiol Endocrinol Metab 2003;284:E741-7.

[74] Chalkley SM, Hettiarachchi M, Chisholm DJ, Kraegen EW. Five-hour fatty acid elevation increases muscle lipids and impairs glycogen synthesis in the rat. Metabolism 1998;47:1121-6.

[75] Yu C, Chen Y, Cline GW, Zhang D, Zong H, Wang Y, et al. Mechanism by Which Fatty Acids Inhibit Insulin Activation of Insulin Receptor Substrate-1 (IRS-1)associated Phosphatidylinositol 3-Kinase Activity in Muscle. J Biol Chem 2002;277:50230-6.

[76] Bajaj M, Suraamornkul S, Romanelli A, Cline GW, Mandarino LJ, Shulman GI, et al. Effect of a sustained reduction in plasma free fatty acid concentration on intramuscular long-chain fatty acyl-coAs and insulin action in type 2 diabetic patients. Diabetes 2005;54:3148-53.

[77] Houmard JA, Tanner CJ, Yu C, Cunningham PG, Pories WJ, MacDonald KG et al. Effect of weight loss on insulin sensitivity and intramuscular long-chain fatty acyl-CoAs in morbidly obese subjects. Diabetes 2002;51: 2959-63.

[78] Bruce CR, Anderson MJ, Carey AL, Newman DG, Bonen A, Kriketos AD, et al. Muscle oxidative capacity is a better predictor of insulin sensitivity than lipid status. J Clin Endocrinol Metab 2003;88:5444-51.

[79] Faergeman NJ, Knudsen J. Role of long-chain fatty acyl-CoA esters in the regulation of metabolism and in cell signalling. Biochem J 1997;323: $1-12$.

[80] Jenkins CM, Yang J, Sims HF, Gross RW. Reversible high affinity inhibition of phosphofructokinase-1 by acyl-CoA. J Biol Chem 2011;286:11937-50.

[81] Koves TR, Ussher JR, Noland RC, Slentz D, Mosedale M, Ilkayeva O, et al. Mitochondrial overload and incomplete fatty acid oxidation contribute to skeletal muscle insulin resistance. Cell Metab 2008;7:45-56.

[82] Violante S, Ijlst L, van Lenthe $H$, de Almeida IT, Wanders RJ, Ventura FV. Carnitine palmitoyltransferase 2: New insights on the substrate specificity and implications for acylcarnitine profiling. Biochim Biophys Acta 2010;1802:728-32.

[83] Bell JA, Reed MA, Consitt LA, Martin OJ, Haynie KR, Hulver MW, et al. Lipid partitioning, incomplete fatty acid oxidation, and insulin signal transduction in primary human muscle cells: effects of severe obesity, fatty acid incubation, and fatty acid translocase/CD36 overexpression. J Clin Endocrinol Metab 2010:jc.2009-1596.

[84] Boyle KE, Canham JP, Consitt LA, Zheng D, Koves TR, Gavin TP, et al. A high-fat diet elicits differential responses in genes coordinating oxidative metabolism in skeletal muscle of lean and obese individuals. J Clin Endocrinol Metab 2010:jc.2010-253.

[85] Gaster M. Reduced lipid oxidation in myotubes established from obese and type 2 diabetic subjects. Biochem Biophys Res Commun 2009;382: 766-70.

[86] Wensaas AJ, Rustan AC, Just M, Berge RK, Drevon CA, Gaster M. Fatty acid incubation of myotubes from humans with type 2 diabetes leads to enhanced release of $\{$ beta\}-oxidation products because of impaired fatty acid oxidation: effects of tetradecylthioacetic acid and eicosapentaenoic Acid. Diabetes 2009;58:527-35.
[87] Huffman KM, Shah SH, Stevens RD, Bain JR, Muehlbauer M, Slentz CA, et al. Relationships between circulating metabolic intermediates and insulin action in overweight to obese, inactive men and women. Diabetes Care 2009;32:1678-83.

[88] Newgard CB, An J, Bain JR, Muehlbauer MJ, Stevens RD, Lien LF, et al. A branched-chain amino acid-related metabolic signature that differentiates obese and lean humans and contributes to insulin resistance. Cell Metab 2009;9:311-26.

[89] Adams SH, Hoppel CL, Lok KH, Zhao L, Wong SW, Minkler PE, et al. Plasma acylcarnitine profiles suggest incomplete long-chain fatty acid beta-oxidation and altered tricarboxylic acid cycle activity in type 2 diabetic AfricanAmerican women. J Nutr 2009;139:1073-81.

[90] Mihalik SJ, Goodpaster BH, Kelley DE, Chace DH, Vockley J, Toledo FGS, et al. Increased levels of plasma acylcarnitines in obesity and type 2 diabetes and identification of a marker of glucolipotoxicity. Obesity 2010;18: 1695-700.

[91] Koves TR, Li P, An J, Akimoto T, Slentz D, Ilkayeva O, et al. Peroxisome proliferator-activated receptor-gamma co-activator 1alpha-mediated metabolic remodeling of skeletal myocytes mimics exercise training and reverses lipid-induced mitochondrial inefficiency. J Biol Chem 2005;280:33588-98.

[92] Redman LM, Huffman KM, Landerman LR, Pieper CF, Bain JR, Muehlbauer MJ, et al. Effect of caloric restriction with and without exercise on metabolic intermediates in nonobese men and women. J Clin Endocrinol Metab 2011;96:E312-21.

[93] Velan SS, Said N, Durst C, Frisbee S, Frisbee J, Raylman RR, et al. Distinct patterns of fat metabolism in skeletal muscle of normal-weight, overweight, and obese humans. Am J Physiol 2008;295:R1060-5

[94] Gimeno RE, Cao J. Thematic Review Series: Glycerolipids. Mammalian glycerol-3-phosphate acyltransferases: new genes for an old activity. J Lipid Res 2008;49:2079-88.

[95] Park H, Kaushik VK, Constant S, Prentki M, Przybytkowski E, Ruderman NB, et al. Coordinate regulation of malonyl-CoA decarboxylase, sn-glycerol-3phosphate acyltransferase, and acetyl-CoA carboxylase by AMP-activated protein kinase in rat tissues in response to exercise. J Biol Chem 2002;277:32571-7

[96] Wurie HR, Buckett L, Zammit VA. Evidence that diacylglycerol acyltransferase1 (DGAT-1) has dual membrane-topology in the endoplasmic reticulum of HePG2 cells. J Biol Chem; in Press, doi: 10.1074/jbc.M111.251900.

[97] McFie PJ, Banman SL, Kary S, Stone SJ. Murine diacylglycerol acyltransferase-2 (DGAT2) can catalyze triacylglycerol synthesis and promote lipid droplet formation independent of its localization to the endoplasmic reticulum. J Biol Chem 2011;286:28235-46.

[98] Stone SJ, Levin MC, Zhou P, Han J, Walther TC, Farese Jr RV. The endoplasmic reticulum enzyme DGAT2 is found in mitochondria-associated membranes and has a mitochondrial targeting signal that promotes its association with mitochondria. J Biol Chem 2009;284:5352-61.

[99] Cases S, Smith SJ, Zheng Y-W, Myers HM, Lear SR, Sande E, et al. Identification of a gene encoding an acyl CoA:diacylglycerol acyltransferase, a key enzyme in triacylglycerol synthesis. Proc Natl Acad Sci 1998;95:13018-23.

[100] Cases S, Stone SJ, Zhou P, Yen E, Tow B, Lardizabal KD, et al. Cloning of DGAT2, a second mammalian diacylglycerol acyltransferase, and related family members. J Biol Chem 2001;276:38870-6.

[101] Li M, Paran C, Wolins NE, Horowitz JF. High muscle lipid content in obesity is not due to enhanced activation of key triglyceride esterification enzymes or to the suppression of lipolytic proteins. Am J Physiol Endocrinol Metab 2011;300:E699-707.

[102] Schenk S, Horowitz JF. Acute exercise increases triglyceride synthesis in skeletal muscle and prevents fatty acid-induced insulin resistance. J Clin Invest 2007;117:1690-8.

[103] Alsted T], Nybo L, Schweiger M, Fledelius C, Jacobsen P, Zimmermann R, et al Adipose triglyceride lipase in human skeletal muscle is upregulated by exercise training. Am J Physiol Endocrinol Metab 2008:90912.2008.

[104] Schmitt B, Fluck M, Decombaz J, Kreis R, Boesch C, Wittwer M, et al. Transcriptional adaptations of lipid metabolism in tibialis anterior muscle of endurance-trained athletes. Physiol Genomics 2003;15:148-57.

[105] Newsom SA, Schenk S, Li M, Everett AC, Horowitz JF. High fatty acid availability after exercise alters the regulation of muscle lipid metabolism. Metabolism 2010;60:852-9.

[106] Liu L, Yu S, Khan RS, Ables GP, Bharadwaj KG, Hu Y, et al. Diacylglycerol acyl transferase 1 deficiency decreases PPAR expression and does not lead lipotoxicity in cardiac and skeletal muscle. J Lipid Res 2010;52:732-44.

[107] Dobrzyn P, Jazurek M, Dobrzyn A. Stearoyl-CoA desaturase and insulin signaling - What is the molecular switch? Biochim Biophys Acta 2010;1797:1189-94.

[108] Wang J, Yu L, Schmidt RE, Su C, Huang X, Gould K, et al. Characterization of HSCD5, a novel human stearoyl-CoA desaturase unique to primates. Biochem Biophys Res Commun 2005;332:735-42.

[109] Dobrzyn P, Pyrkowska A, Jazurek M, Szymanski K, Langfort J, Dobrzyn A Endurance training-induced accumulation of muscle triglycerides is coupled to upregulation of stearoyl-CoA desaturase 1. J Appl Physiol 2010;109:1653-61.

[110] Peter A, Weigert C Staiger $\mathrm{H}$, Machicao F, Schick F. Machann $\mathrm{Jr}$, et al. Individual stearoyl-CoA desaturase 1 expression modulates endoplasmic reticulum stress and inflammation in human myotubes and is sssociated with skeletal muscle lipid storage and insulin sensitivity in vivo. Diabetes 2009;58:1757-65. 
[111] Pinnamaneni S, Southgate R, Febbraio M, Watt M. Stearoyl CoA desaturase 1 is elevated in obesity but protects against fatty acid-induced skeletal muscle insulin resistance in vitro. Diabetologia 2006;49:3027-37.

[112] Hulver MW, Berggren JR, Carper MJ, Miyazaki M, Ntambi JM, Hoffman EP, et al. Elevated stearoyl-CoA desaturase-1 expression in skeletal muscle contributes to abnormal fatty acid partitioning in obese humans. Cell Metab $2005 ; 2: 251-61$.

[113] Zimmermann R, Strauss JG, Haemmerle G, Schoiswohl G, Birner-Gruenberger $\mathrm{R}$, Riederer $\mathrm{M}$, et al. Fat mobilization in adipose tissue is promoted by adipose triglyceride lipase. Science 2004;306:1383-6.

[114] Fredrikson G, Belfrage P. Positional specificity of hormone-sensitive lipase from rat adipose tissue. J Biol Chem 1983;258:14253-6.

[115] Haemmerle G, Zimmermann R, Hayn M, Theussl C, Waeg G, Wagner E, et al. Hormone-sensitive lipase deficiency in mice causes diglyceride accumulation in adipose tissue, muscle, and testis. J Biol Chem 2002;277: 4806-15.

[116] Blaak E, Schiffelers S, Saris W, Mensink M, Kooi M. Impaired $\beta$-adrenergically mediated lipolysis in skeletal muscle of obese subjects. Diabetologia 2004; 47:1462-8.

[117] Badin PM, Louche K, Mairal A, Liebisch G, Schmitz G, Rustan AC, et al. Altered skeletal muscle lipase expression and activity contribute to insulin resistance in humans. Diabetes 2011;60:1734-42.

[118] Granneman JG, Moore H-PH, Krishnamoorthy R, Rathod M. Perilipin controls lipolysis by regulating the interactions of AB-hydrolase containing 5 (Abhd5) and adipose triglyceride lipase (Atgl). J Biol Chem 2009;284: 34538-44.

[119] Granneman JG, Moore H-PH, Mottillo EP, Zhu Z, Zhou L. Interactions of perilipin-5 (PLIN5) with adipose trigylceride lipase (ATGL). J Biol Chem 2011;286:5126-35.

[120] Granneman JG, Moore HP, Mottillo EP, Zhu Z. Functional interactions between MLDP (LSDP5) and ABHD5 in the control of intracellular lipid accumulation. J Biol Chem 2009;284:3049-57.

[121] Wang H, Bell M, Sreenevasan U, Hu H, Liu J, Dalen K, et al. Unique regulation of adipose triglyceride lipase (ATGL) by perilipin 5, a lipid droplet-associated protein. J Biol Chem 2011;286:15707-15.

[122] Van Loon LJC. Use of intramuscular triacylglycerol as a substrate source during exercise in humans. J Appl Physiol 2004;97:1170-87.

[123] Stellingwerff T, Boon H, Jonkers RAM, Senden JM, Spriet LL, Koopman R, et al. Significant intramyocellular lipid use during prolonged cycling in endurancetrained males as assessed by three different methodologies. Am J Physiol Endocrinol Metab 2007;292:E1715-23.

[124] Standl E, Lotz N, Dexel T, Janka H, Kolb H. Muscle triglycerides in diabetic subjects. Diabetologia 1980;18:463-9.

[125] Van Loon LJC, Goodpaster B. Increased intramuscular lipid storage in the insulin-resistant and endurance-trained state. Pflügers Arch 2006;451:606-16.

[126] Bassel-Duby R, Olson EN. Signaling pathways in skeletal muscle remodeling. Annu Rev Biochem 2006;75:19-37.

[127] Lillioja S, Young AA, Culter CL, Ivy JL, Abbott WG, Zawadzki JK, et al. Skeletal muscle capillary density and fiber type are possible determinants of in vivo insulin resistance in man. J Clin Invest 1987;80:415-24.

[128] Beller M, Thiel K, Thul PJ, Jäckle H. Lipid droplets: A dynamic organelle moves into focus. FEBS Lett 2010;584:2176-82.

[129] Farese RV, Walther TC. Lipid droplets finally get a little R-E-S-P-E-C-T. Cell 2009;139:855-60

[130] Thiele C, Spandl J. Cell biology of lipid droplets. Curr Opin Cell Biol 2008;20:378-85.

[131] Walther TC, Farese Jr RV. The life of lipid droplets. Biochim Biophys Acta 2009;1791:459-66.

[132] DiAugustine RP, Schaefer JM, Fouts JR. Hepatic lipid droplets. Isolation, morphology and composition. Biochem J 1973;132:323-7.

[133] Minnaard R, Schrauwen P, Schaart G, Jorgensen JA, Lenaers E, Mensink M, et al. Adipocyte differentiation-related protein and OXPAT in rat and human skeletal muscle: involvement in lipid accumulation and type 2 diabetes mellitus. J Clin Endocrinol Metab 2009;94:4077-85.

[134] Phillips SA, Choe CC, Ciaraldi TP, Greenberg AS, Kong AP, Baxi SC, et al. Adipocyte differentiation-related protein in human skeletal muscle: relationship to insulin sensitivity. Obes Res 2005;13:1321-9.

[135] Prats C, Donsmark M, Qvortrup K, Londos C, Sztalryd C, Holm C, et al. Decrease in intramuscular lipid droplets and translocation of HSL in response to muscle contraction and epinephrine. J Lipid Res 2006; 47:2392-9.

[136] Wolins NE, Skinner JR, Schoenfish MJ, Tzekov A, Bensch KG, Bickel PE. Adipocyte protein S3-12 coats nascent lipid droplets. J Biol Chem 2003;278:37713-21.

[137] Dalen KT, Dahl T, Holter E, Arntsen B, Londos C, Sztalryd C, et al. LSDP5 is a PAT protein specifically expressed in fatty acid oxidizing tissues. Biochim Biophys Acta 2007;1771:210-27.

[138] Wolins NE, Quaynor BK, Skinner JR, Tzekov A, Croce MA, Gropler MC, et al. OXPAT/PAT-1 is a PPAR-induced lipid droplet protein that promotes fatty acid utilization. Diabetes 2006;55:3418-28.

[139] Yamaguchi T, Matsushita S, Motojima K, Hirose F, Osumi T. MLDP, a novel PAT family protein localized to lipid droplets and enriched in the heart, is regulated by peroxisome proliferator-activated receptor alpha. J Biol Chem 2006;281:14232-40.

[140] Bell M, Wang H, Chen H, McLenithan JC, Gong DW, Yang RZ, et al. Consequences of lipid droplet coat protein downregulation in liver cells: abnormal lipid droplet metabolism and induction of insulin resistance. Diabetes 2008;57:2037-45.

[141] Miyoshi H, Souza SC, Endo M, Sawada T, Perfield II JW, Shimizu C, et al. Perilipin overexpression in mice protects against diet-induced obesity. J Lipid Res 2009;51:975-82.

[142] Wang H, Sreenevasan U, Hu H, Saladino A, Polster BM, Lund LM, et al Perilipin 5, lipid droplet associated protein provides physical and metabolic linkage to mitochondria. J Lipid Res; in Press, doi: 10.1194/ jlr.M017939.

[143] Bosma M, Minnaard R, Sparks LM, Schaart G, Losen M, De Baets MH, et al. The lipid droplet coat protein perilipin 5 also localizes to muscle mitochondria. Histochem Cell Biol; in press, doi:10.1007/s00418-011-0888-x.

[144] Chang BH-J, Li L, Saha P, Chan L. Absence of adipose differentiation related protein upregulates hepatic VLDL secretion, relieves hepatosteatosis and improves whole body insulin resistance in leptin-deficient mice. J Lipid Res 2010;51:2132-42.

[145] Imai Y, Varela GM, Jackson MB, Graham MJ, Crooke RM, Ahima RS. Reduction of hepatosteatosis and lipid levels by an adipose differentiation-related protein antisense oligonucleotide. Gastroenterology 2007:132:1947-54.

[146] Varela GM, Antwi DA, Dhir R, Yin X, Singhal NS, Graham MJ, et al. Inhibition of ADRP prevents diet-induced insulin resistance. Am J Physiol Gastrointest Liver Physiol 2008;295:G621-8.

[147] Corella D, Qi L, Tai ES, Deurenberg-Yap M, Tan CE, Chew SK, et al. Perilipin gene variation determines higher susceptibility to insulin resistance in Asian women when consuming a high-saturated fat, low-carbohydrate diet. Diabetes Care 2006;29:1313-9.

[148] Jang Y, Kim OY, Lee JH, Koh SJ, Chae JS, Kim JY, et al. Genetic variation at the perilipin locus is associated with changes in serum free fatty acids and abdominal fat following mild weight loss. Int J Obes 2006;30:1601-8.

[149] Qi L, Corella D, Sorlí JV, Portolés O, Shen H, Coltell O, et al. Genetic variation at the perilipin (PLIN) locus is associated with obesity-related phenotypes in White women. Clin Genet 2004;66:299-310.

[150] Davoli R, Gandolfi G, Braglia S, Comella M, Zambonelli P, Buttazzoni L, et al New SNP of the porcine Perilipin 2 (PLIN2) gene, association with carcass traits and expression analysis in skeletal muscle. Mol Biol Rep 2011;38:1575-83.

[151] Matsusue K, Kusakabe T, Noguchi T, Takiguchi S, Suzuki T, Yamano S, et al Hepatic steatosis in leptin-deficient mice is promoted by the PPAR $\gamma$ target gene Fsp27. Cell Metab 2008;7:302-11.

[152] Puri V, Konda S, Ranjit S, Aouadi M, Chawla A, Chouinard M, et al. Fat-specific protein 27 , a novel lipid droplet protein that enhances triglyceride storage. J Biol Chem 2007;282:34213-8.

[153] Wang ZQ, Yu Y, Zhang XH, Floyd EZ, Cefalu WT. Human adenovirus 36 decreases fatty acid oxidation and increases de novo lipogenesis in primary cultured human skeletal muscle cells by promoting Cidec/FSP27 expression. Int J Obes 2010.

[154] Gross DA, Snapp EL, Silver DL. Structural insights into triglyceride storage mediated by fat storage-inducing transmembrane (FIT) protein 2. PLoS ONE 2010;5:e10796

155] Kadereit B, Kumar P, Wang W-J, Miranda D, Snapp EL, Severina N, et al. Evolutionarily conserved gene family important for fat storage. Proc Natl Acad Sci 2008;105:94-9.

[156] Bostrom P, Andersson L, Rutberg M, Perman J, Lidberg U, Johansson BR, et al. SNARE proteins mediate fusion between cytosolic lipid droplets and are implicated in insulin sensitivity. Nat Cell Biol 2007;9:1286-93.

[157] Jägerström S, Polesie S, Wickström Y, Johansson BR, Schröder HD, Højlund K et al. Lipid droplets interact with mitochondria using SNAP23. Cell Biol Int 2009;33:934-40.

[158] Schlaepfer IR, Pulawa LK, Ferreira LDMCB, James DE, Capell WH, Eckel RH Increased expression of the SNARE accessory protein Munc18c in lipidmediated insulin resistance. J Lipid Res 2003;44:1174-81.

[159] Sollner TH. Lipid droplets highjack SNAREs. Nat Cell Biol 2007;9: 1219-20.

[160] Boström P, Andersson L, Li L, Perkins R, Højlund K, Borén J, et al. The assembly of lipid droplets and its relation to cellular insulin sensitivity. Biochem Soc Trans 2009;037:981-5.

[161] Boström P, Andersson L, Vind B, Håversen L, Rutberg M, Wickström Y, et al. The SNARE protein SNAP23 and the SNARE-interacting protein Munc18c in human skeletal muscle are implicated in insulin resistance/type 2 diabetes. Diabetes 2010;59:1870-8.

[162] Ducharme NA, Bickel PE. Lipid droplets in lipogenesis and lipolysis Endocrinology 2008;149:942-9.

[163] Olofsson SO, Andersson L, Håversen L, Olsson C, Myhre S, Rutberg M, et al. The formation of lipid droplets: possible role in the development of insulin resistance/type 2 diabetes. Prostaglandins Leukot Essent Fatty Acids 2011; in Press, doi: 10.1016/j.plefa.2011.04.019.

[164] He J, Goodpaster BH, Kelley DE. Effects of weight loss and physical activity on muscle lipid content and droplet size. Obesity 2004;12:761-9.

[165] Molero JC, Lee S, Leizerman I, Chajut A, Cooper A, Walder K. Effects of rosiglitazone on intramyocellular lipid accumulation in Psammomys obesus. Biochim Biophys Acta 2010;1802:235-9.

[166] Fraenkel M, Weiss R, Leizerman I, Anaby D, Golomb E, Leibowitz G, et al. Scanning electron microscopic analysis of intramyocellular lipid droplets in an animal model of type 2 diabetes. Obesity 2008;16:695-9.

[167] Tarnopolsky MA, Rennie CD, Robertshaw HA, Fedak-Tarnopolsky SN, Devries MC, Hamadeh MJ. Influence of endurance exercise training and sex on 
intramyocellular lipid and mitochondrial ultrastructure, substrate use, and mitochondrial enzyme activity. Am J Physiol Regul Integr Comp Physiol 2007;292:R1271-8.

[168] Malenfant P, Joanisse DR, Theriault R, Goodpaster BH, Kelley DE, Simoneau JA Fat content in individual muscle fibers of lean and obese subjects. Int J Obes Relat Metab Disord 2001;25:1316-21.

[169] Nielsen J, Mogensen M, Vind BF, Sahlin K. HÃ,jlund K, SchrÃ, der HD, et al Increased subsarcolemmal lipids in type 2 diabetes: effect of training on localization of lipids, mitochondria, and glycogen in sedentary human skeletal muscle. Am J Physiol Endocrinol Metab 2009;298:E706-13.
[170] Hoppeler H, Luthi P, Claassen H, Weibel ER, Howald H. The ultrastructure of the normal human skeletal muscle. A morphometric analysis on untrained men, women and well-trained orienteers. Pflugers Arch 1973;344: 217-32.

[171] Taylor CR, Weibel ER, Weber JM, Vock R, Hoppeler H, Roberts TJ, et al. Design of the oxygen and substrate pathways. I. Model and strategy to test symmorphosis in a network structure. J Exp Biol 1996;199:1643-9.

[172] Vock R, Hoppeler H, Claassen H, Wu DX, Billeter R, Weber JM, et al. Design of the oxygen and substrate pathways. VI. structural basis of intracellular substrate supply to mitochondria in muscle cells. J Exp Biol 1996;199:1689-97. 